\title{
Ionic Dendrimer Based Polyamide Membranes for Ion Separation
}

Ze-Lin Qiu, ${ }^{\dagger}$ Li-Feng Fang, ${ }^{\dagger}$ Yu-Jie Shen, ${ }^{\dagger}$ Wen-Han $\mathrm{Yu},{ }^{\dagger}$ Bao-Ku Zhu,,${ }^{, \dagger}$ Claus HélixNielsen, $*, \neq, \S$ and Wenjing Zhang ${ }^{\ddagger}$

†Key Laboratory of Macromolecule Synthesis and Functionalization (Ministry of Education), ERC of Membrane and Water Treatment (Ministry of Education), Department of Polymer Science and Engineering, Zhejiang University, Hangzhou 310027, China

‡Technical University of Denmark, Department of Environmental Engineering, Bygningstorvet 115, 2800 Kgs., Lyngby, Denmark

${ }^{\S}$ Laboratory for Water Biophysics and Membrane Processes, Faculty of Chemistry and Chemical Engineering, University of Maribor, Smetanova ulica 17, 2000 Maribor, Slovenia

*Corresponding authors. E-mail: zhubk@zju.edu.cn (B.Z.); clhe@env.dtu.dk (C.H.). 
Section S1. Schematic Illustration of the Ionic Polyamidoamine (PAMAM)

Dendrimer Based Interfacial Polymerization (IP) Process and the Network

Structures of the Corresponding Polyamide (PA) Membranes

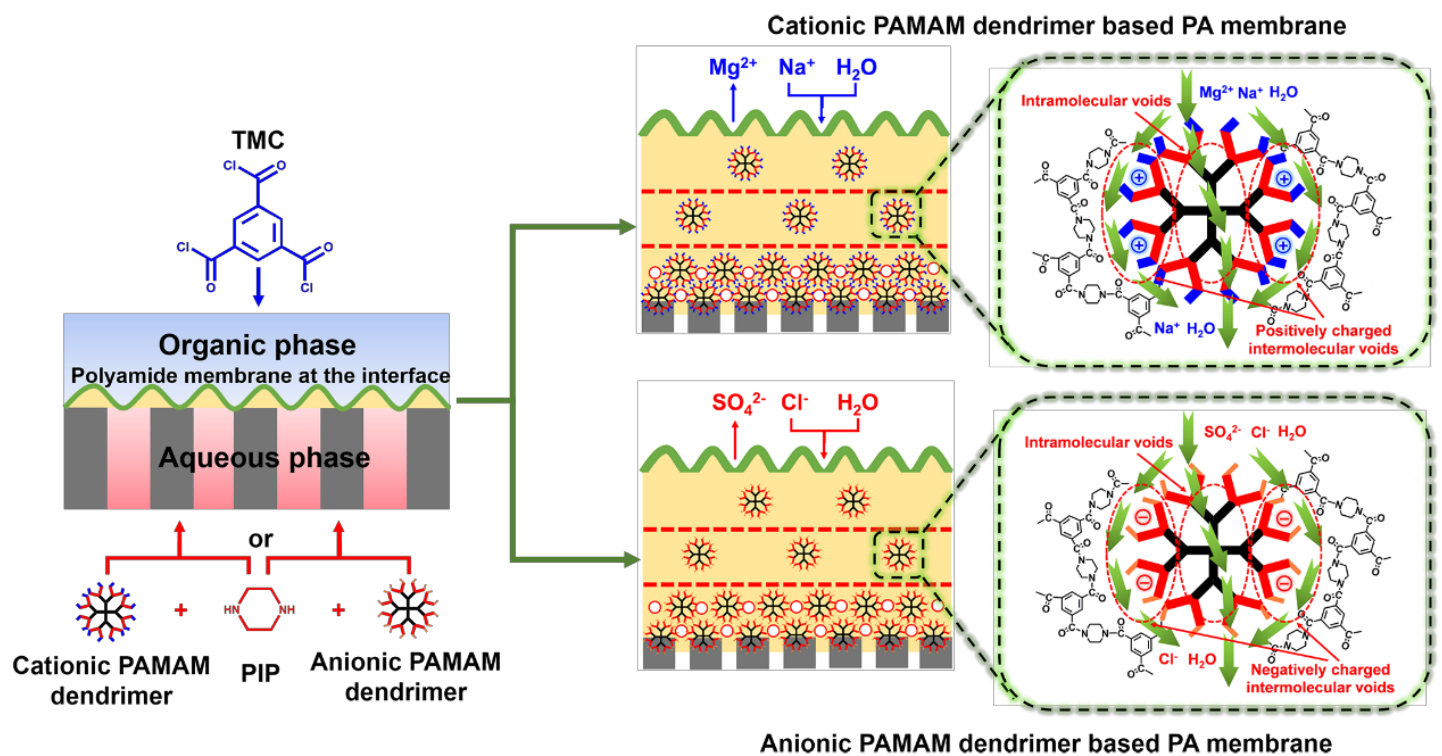

Figure S1. Schematic illustration of the cationic and anionic PAMAM dendrimer based IP process and the network structures of the corresponding PA membranes. 


\section{Section S2. Structure of Generation 5 Polyamidoamine (PAMAM G5-NH2)}

As illustrated in Figure S2, PAMAM G5-NH2 with molecular weight of $28826 \mathrm{~g}$ $\mathrm{mol}^{-1}$ consists of a core, internal amidoamine branching units and 128 primary amine terminal groups. Compared with linear polymers, PAMAM G5-NH2 is a kind of macromolecule with three-dimensional (3D) architecture, which has high molecular monodispersity in aqueous solution. Contributed by intramolecular voids inside PAMAM G5-NH2 and moderate distance between two terminal amine groups (Z-Z distance), the access of water molecules and ions through the PAMAM G5- $\mathrm{NH}_{2}$ is allowed, endowing it with encapsulation and nanoscale transport/sieving properties. So that PAMAM G5-NH 2 can be seen as unimolecular container and porous nanoparticle. ${ }^{1}$

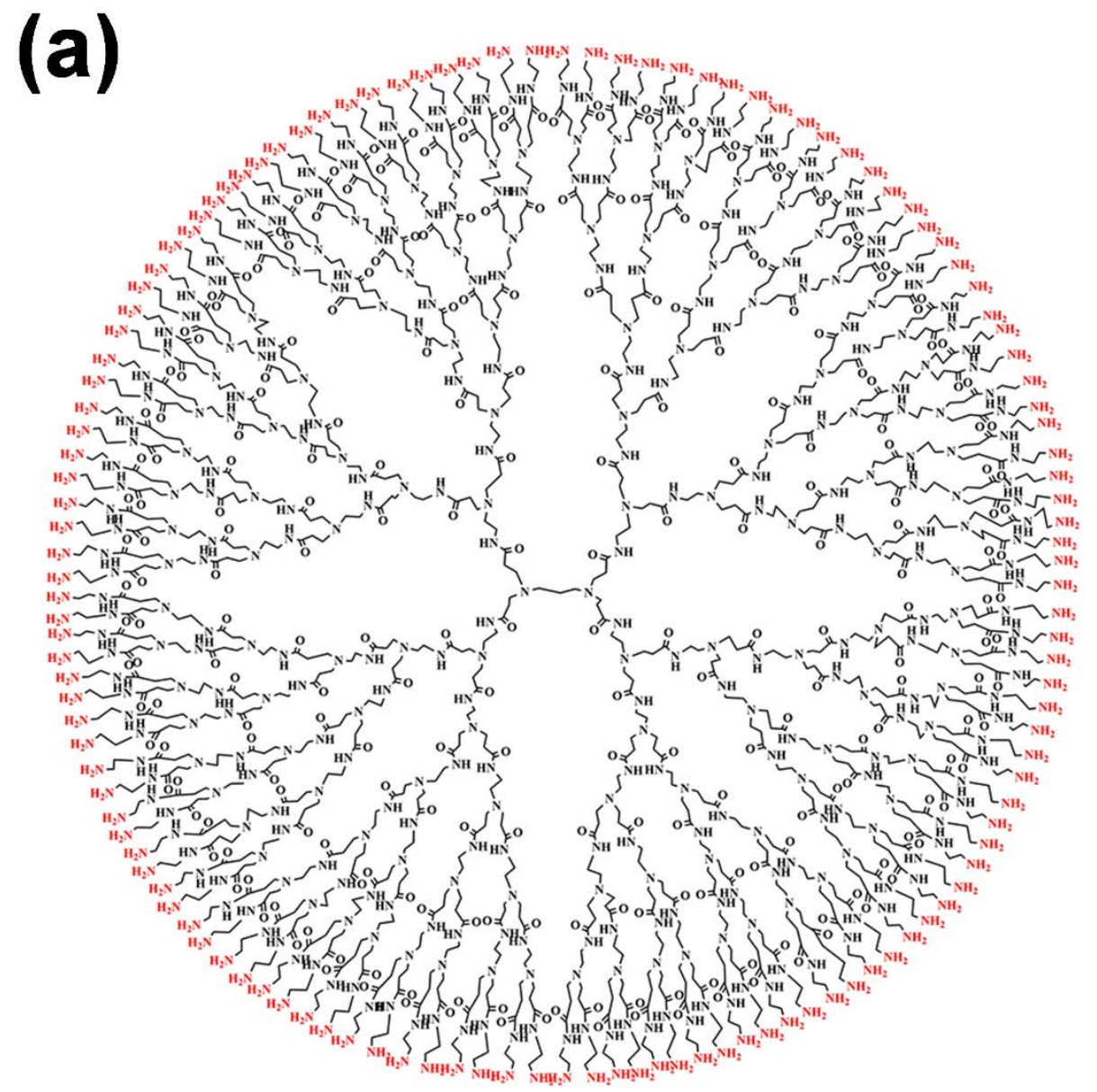




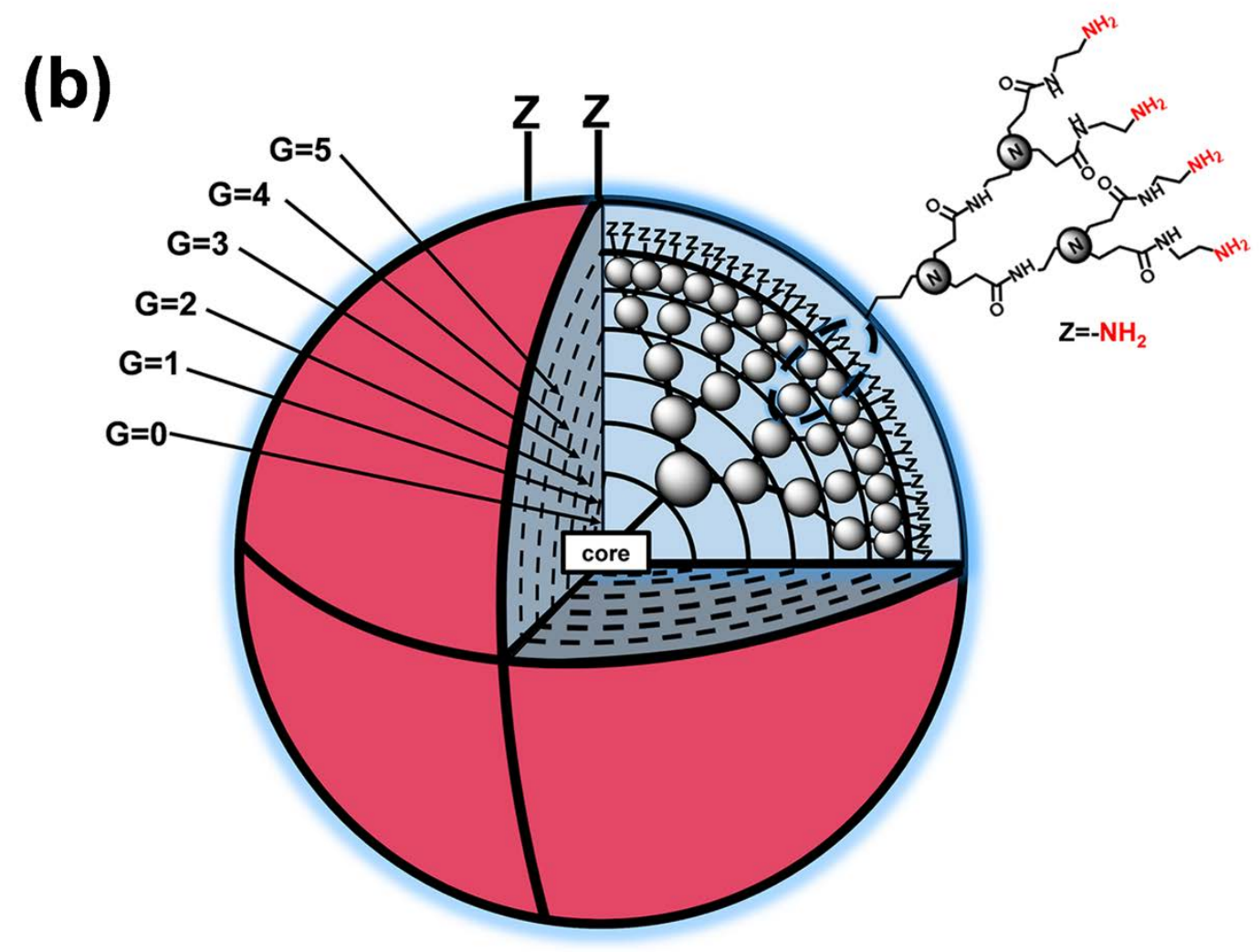

Figure S2. (a) Molecular fomula of PAMAM G5-NH2; (b) Schematic illustration of threedimensional architecture of PAMAM G5- $\mathrm{NH}_{2}$.

Table S1. Characteristics of PAMAM G5-NH2

\begin{tabular}{ccccc}
\hline PAMAM & $\mathrm{M}_{\mathrm{w}}\left(\mathrm{g} \mathrm{mol}^{-1}\right)$ & Chemical formula & Surface groups & Z-Z distance (nm) \\
\hline $\mathrm{G} 5-\mathrm{NH}_{2}$ & 28826 & $\mathrm{C}_{1262} \mathrm{H}_{2528} \mathrm{~N}_{506} \mathrm{O}_{252}$ & 128 & 0.952 \\
\hline
\end{tabular}




\section{Section S3. Characterization of PAMAM Dendrimers}

Compared with PAMAM G5-NH2, the adsorption peaks at 1120 and $1030 \mathrm{~cm}^{-1}$ (C-O stretching vibration) appear for PAMAM G5-TAC (Figure. S3a1 and S3a2). The ${ }^{1} \mathrm{H}$ NMR spectrum of PAMAM G5-TAC exhibiting shifts at 3.25 and $4.35 \mathrm{ppm}$ are assigned to $-\mathrm{N}^{+}\left(\mathrm{CH}_{3}\right)_{3}$ and methyne hydrogen of $-\mathrm{CH}(\mathrm{OH})$ - respectively, ${ }^{2}$ which confirms the successful synthesis of PAMAM G5-TAC (Figure. S3b1 and S3b2). For PAMAM G5-PS, the adsorption peaks at 1185 and $1037 \mathrm{~cm}^{-1}$ can be attributed to $-\mathrm{SO}_{3}{ }^{-}$ group (Figure. S3a1 and S3a3), while different peaks for methylene protons are observed at 2.00, 2.96, 3.07 and $3.57 \mathrm{ppm}$ due to the introduction of $-\left(\mathrm{CH}_{2}\right)_{3} \mathrm{SO}_{3}{ }^{-3}$, which confirms the successful synthesis of PAMAM G5-PS (Figure. S3b1 and S3b3). The sizes of PAMAM G5-NH2, PAMAM G5-TAC and PAMAM G5-PS were measured by DLS, and their sizes increases from 5.6, 7.9 to $9.7 \mathrm{~nm}$ (Figure. S3c1-c3), which can be attributed to extension of molecular chains in water and formed larger hydration layer. ${ }^{4}$ Meanwhile, the zeta potential of PAMAM G5-NH2, PAMAM G5-TAC and PAMAM G5-PS are 4.5, 32.8 and $-31.7 \mathrm{mV}$, respectively, suggesting that PAMAM G5TAC is positively charged while PAMAM G5-PS is negatively charged. 

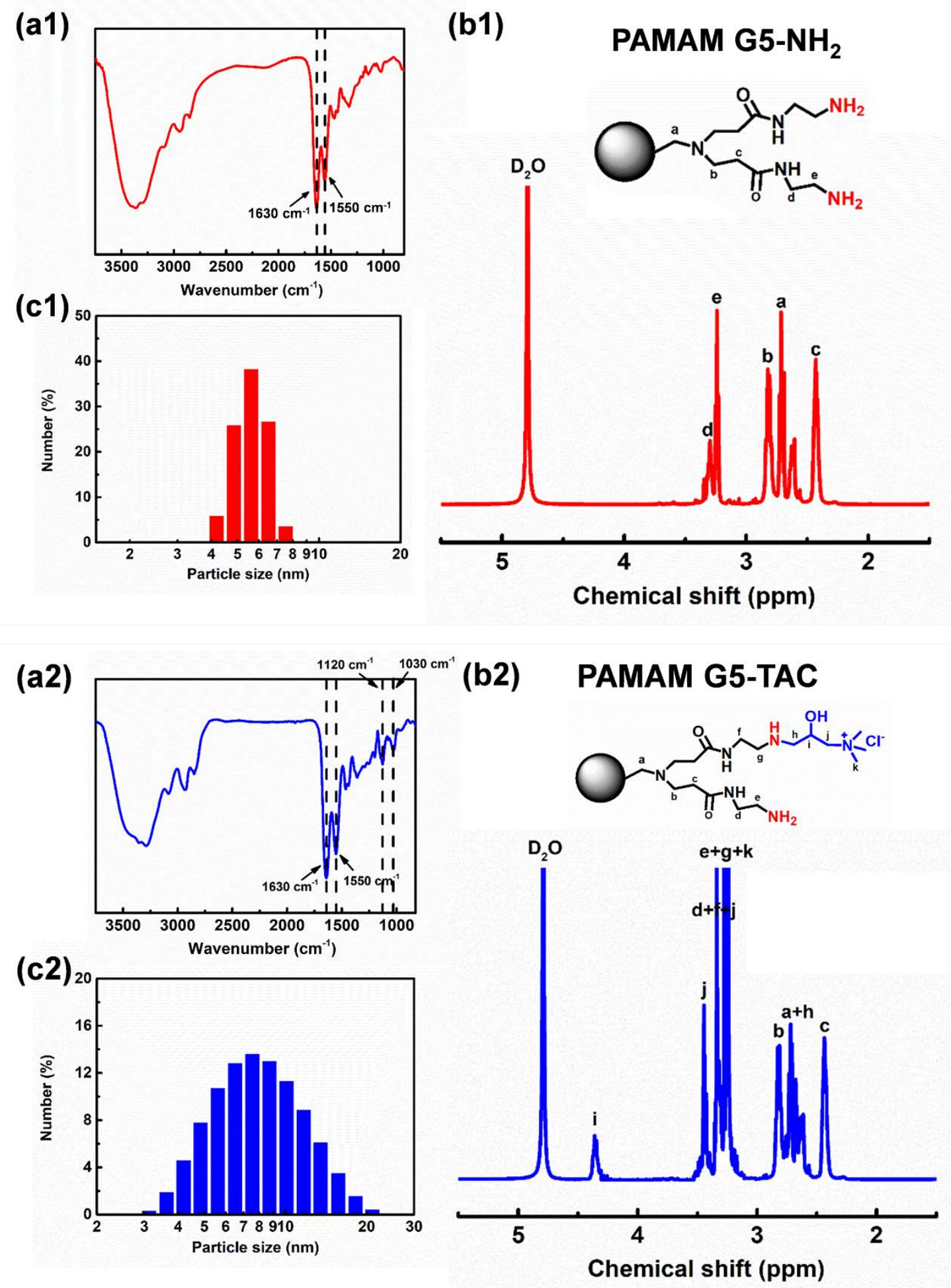
(a3)

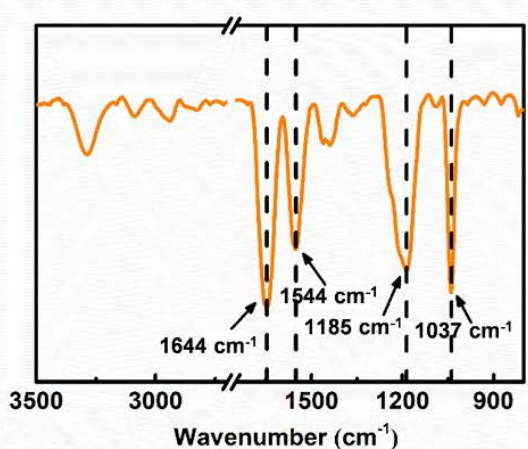

(c3)

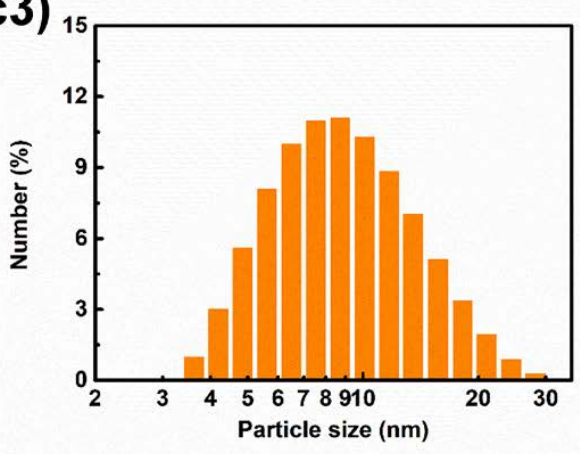

(b3)

PAMAM G5-PS

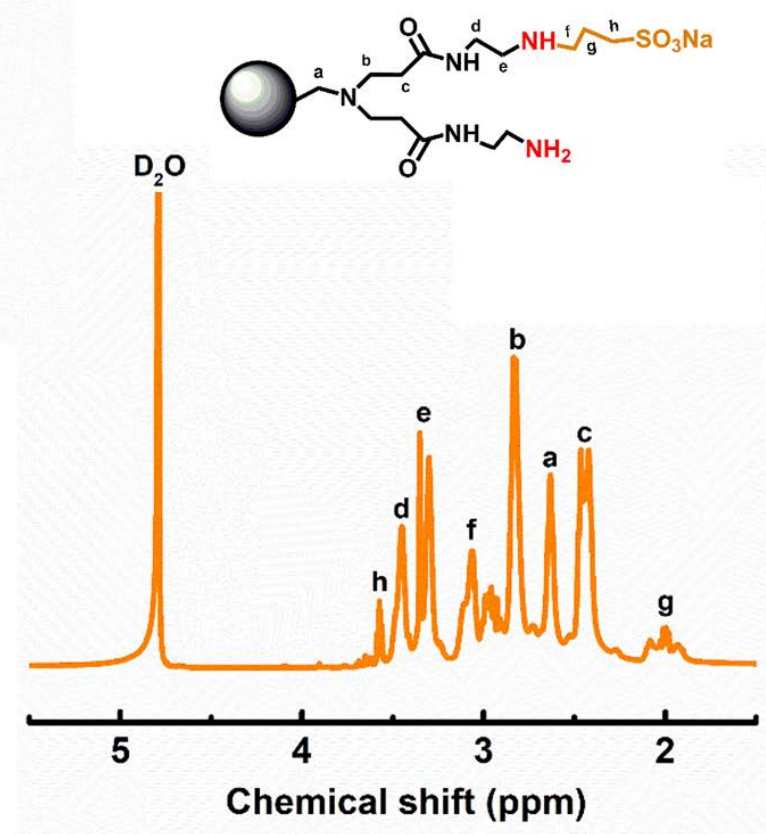

Figure S3. (a1-a3) FTIR spectrum of PAMAM G5-NH2, PAMAM G5-TAC and PAMAM G5PS; (b1-b3) ${ }^{1} \mathrm{H}$ NMR spectrum of PAMAM G5- $\mathrm{NH}_{2}$, PAMAM G5-TAC and PAMAM G5-PS; (c1-c3) DLS images of PAMAM G5-NH2, PAMAM G5-TAC and PAMAM G5-PS. 
Section S4. Characterization of the PSF-UF Flat Sheet Substrate

(a)

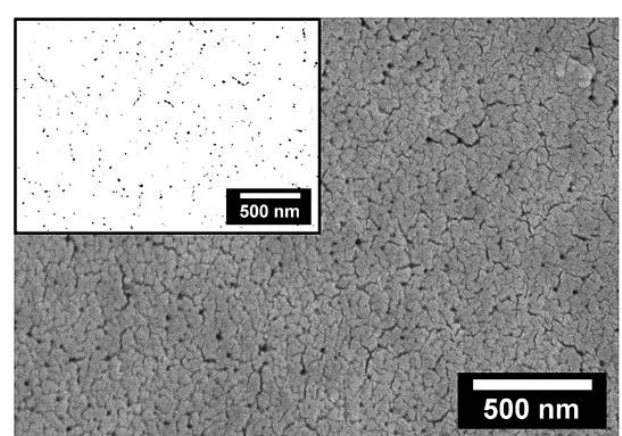

(b)

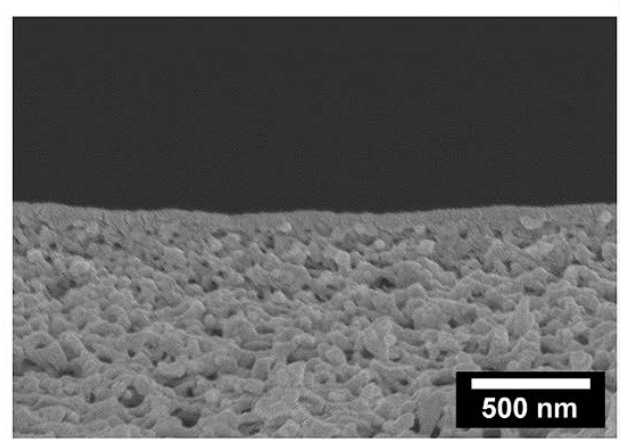

Figure S4. (A) FESEM images and the corresponding binary images of the surface morphology for PSF-UF flat sheet substrate; (B) FESEM images for the cross section of the PSF-UF flat sheet substrate.

Table S2. Pure Water Permeability, Surface Porosity, Bulk Porosity and MWCO of the PSF-UF Flat Sheet Substrate

\begin{tabular}{ccccc}
\hline Substrate & $\begin{array}{c}\text { Pure water permeability } \\
\left(\mathrm{L} \mathrm{m}^{-2} \mathrm{~h}^{-1} \mathrm{MPa}^{-1}\right)\end{array}$ & $\begin{array}{c}\text { Surface porosity } \\
(\%)\end{array}$ & $\begin{array}{c}\text { Bulk porosity } \\
(\%)\end{array}$ & $\begin{array}{c}\text { Molecular weight cut-off } \\
\text { (MWCO) (Da) }\end{array}$ \\
\hline PSF-UF & 1200 & 0.76 & 51.8 & $100 \mathrm{k}$ \\
\hline
\end{tabular}




\section{Section S5. Optimization of G5-NH2/PIP Membrane Preparation Conditions}

As PAMAM G5- $\mathrm{NH}_{2}$ is expected to enable the membrane with faster transport of water molecules, PAMAM G5- $\mathrm{NH}_{2}$ was mixed with piperazine (PIP) in the aqueous phase solution for IP. With the addition of PAMAM G5- $\mathrm{NH}_{2}$ in the aqueous phase solution, the permeate flux is improved, while magnesium sulfate $\left(\mathrm{MgSO}_{4}\right)$ rejection of the membrane is almost unchanged (Figure S5a). Nevertheless, with a further increase of PAMAM G5-NH2 content in the PAMAM G5-NH2/PIP mixture from 70\% to $90 \%$, the PA membranes exhibit a significant drop of both permeate flux and $\mathrm{MgSO}_{4}$ rejection, which can be probably attributed to the increased thickness of selective layer caused by increase of PAMAM G5-NH2 concentration, as well as more defects formed in the selective layer during the IP process caused by lower PIP concentration and disturbance of PAMAM G5-NH2. ${ }^{5}$ In order to confirm the real impact of PAMAM G5$\mathrm{NH}_{2}$ on the improvement of permeate flux, a series of PA membranes without any addition of PAMAM G5-NH2 were prepared by IP in the same reaction conditions. The

results indicate that the PA membranes containing PAMAM G5- $\mathrm{NH}_{2}$ show higher permeate flux when PIP concentration in two aqueous phase solutions are the same (Figure S5b). 

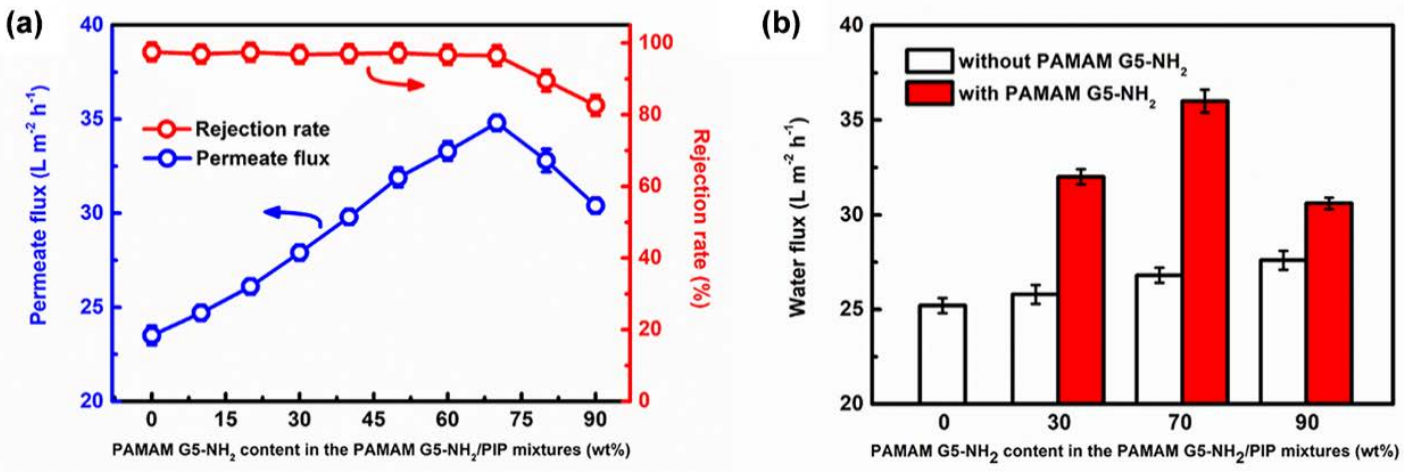

Figure S5. (a) Effect of PAMAM G5-NH $\mathrm{NH}_{2}$ content in the PAMAM G5-NH $/$ /PIP mixtures on the separation performance of the PA membranes when total amine concentration was fixed at $2.0 \mathrm{wt} \%$, TMC concentration was fixed at $0.05 \mathrm{wt} \%$, aqueous phase immersion time was fixed at $5 \mathrm{~min}$ and IP time was fixed at $40 \mathrm{~s}\left(1 \mathrm{~g} \mathrm{~L}^{-1}\right.$ aqueous $\mathrm{MgSO}_{4}$ solution, $25{ }^{\circ} \mathrm{C}$, and 0.4 MPa); (b) The water flux of the PA membranes with or without PAMAM G5- $\mathrm{NH}_{2}\left(25^{\circ} \mathrm{C}\right.$, and $0.4 \mathrm{MPa})$.

When the PAMAM G5-NH2/PIP mixing ratio is fixed at 70/30 (w/w), a lower monomer concentration leads to a selective layer with lower cross-linking density, resulting in poor rejection to $\mathrm{MgSO}_{4}$, while a further increment of monomer concentration leads to the formation of a denser selective layer, resulting in low permeate flux (Figure S6a and S6b). The substrate is allowed to immerse for $5 \mathrm{~min}$ in the aqueous phase solution to absorb adequate monomer for IP. It is likely that a shorter immersion time give a deficit of aqueous monomer for the formation of a uniform and dense selective layer, while an extended immersion time results in thicker selective layer (Figure S6c). In the subsequent IP process, $40 \mathrm{~s}$ is adopted as the optimal immersion time in the organic phase solution. The longer IP time results in a selective layer with higher cross-linking density, lower permeate flux and higher $\mathrm{MgSO}_{4}$ rejection as a consequence (Figure S6d). These experiments show that G5- $\mathrm{NH}_{2} / \mathrm{PIP}$ membrane can be fabricated when optimal membrane preparation parameters are 
adopted.

(a)

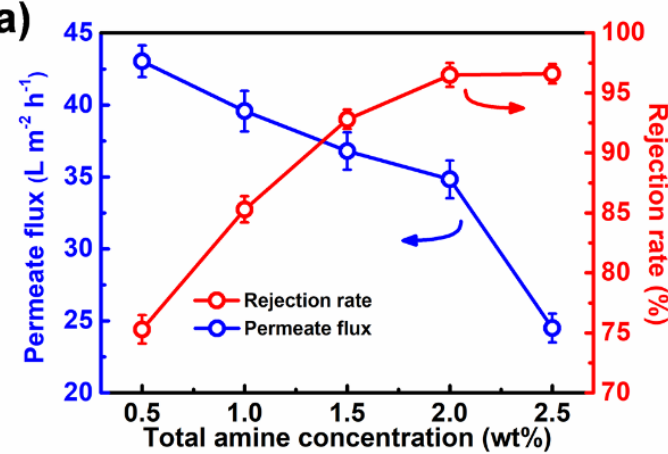

(c)

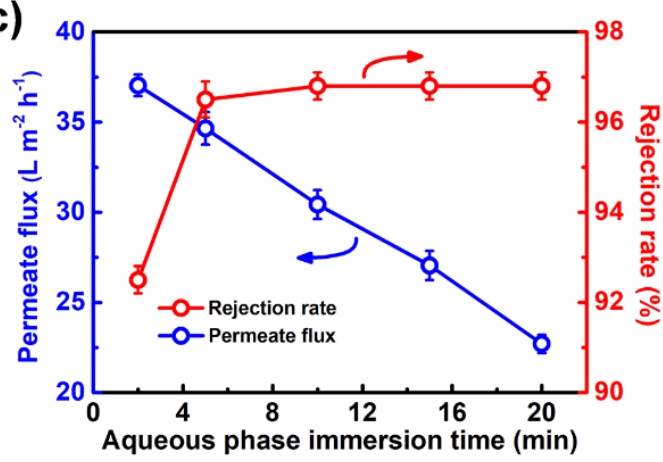

(b)

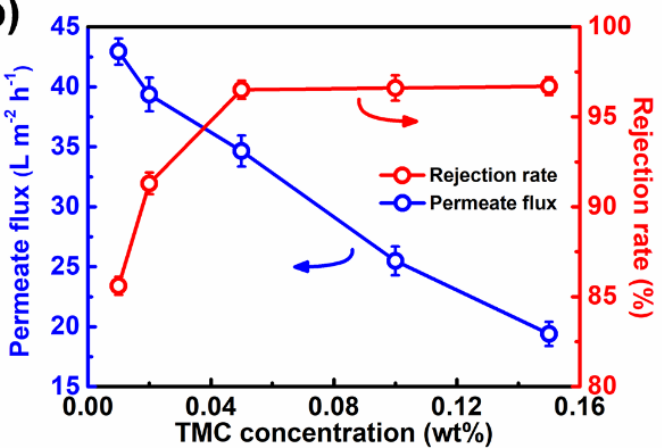

(c)

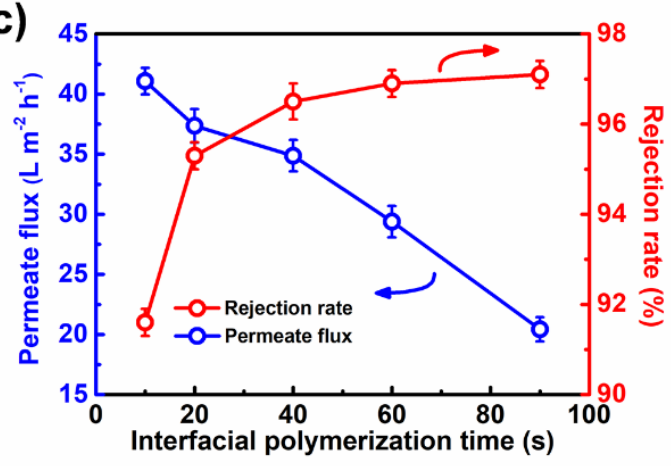

Figure S6. Effects of (a) total amine concentration, (b) TMC concentration, (c) aqueous phase immersion time, and (d) interfacial polymerization time on the separation performance of the PA membranes when the PAMAM G5-NH2/PIP mixing ratio is fixed at 70/30 (w/w) $\left(1 \mathrm{~g} \mathrm{~L}^{-1}\right.$ aqueous $\mathrm{MgSO}_{4}$ solution, $2{ }^{\circ} \mathrm{C}$, and $0.4 \mathrm{MPa}$ ). 


\section{Section S6. Chemical Composition of the PA Membranes}

For ATR-FTIR analysis of the sample, the penetration depth of the infrared (IR) beam into the membrane surface is more than $500 \mathrm{~nm},{ }^{6}$ and thereby the whole PA membrane was detected. It can be inferred that the IP reaction successfully occurred as the appearance of the typical characteristic peak of the tertiary amide at $1663 \mathrm{~cm}^{-1}(\mathrm{C}=\mathrm{O}$ stretching). ${ }^{7}$ Compared with the PIP only membrane, the absorption peak at $1544 \mathrm{~cm}^{-1}$ due to the $\mathrm{N}-\mathrm{H}$ bending and $\mathrm{C}-\mathrm{N}$ stretching of the secondary amide belonging to PAMAM dendrimers appeared for the other three PA membranes, indicating the existence of PAMAM dendrimers in the PA membranes (Figure S7) ${ }^{8}$

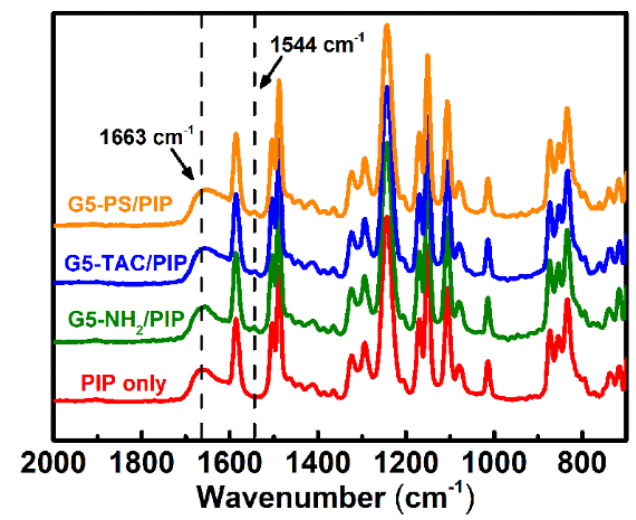

Figure S7. ATR-FTIR spectrum of the PA membranes.

Since the detection depth of XPS measurement is only $8.7 \mathrm{~nm}$ (with a photoelectron take-off angle of $60^{\circ}$ ), only the top surface of the PA membrane can be detected. ${ }^{9}$ Thus, XPS was employed to do more precise characterization of the surface chemical composition of the selective layer (Figure S8a), and the corresponding elemental atomic percentages detected by XPS are listed in Table S3. The much higher nitrogen element content of G5-TAC/PIP membrane and the appearance of sulfur 
element for G5-PS/PIP membrane suggest that there must be additional nitrogen sources or sulfur sources in the PA membrane surface, which is most likely attributed to the presence of different terminal ionizable groups on PAMAM dendrimer molecule surface. To directly confirm the existence of PAMAM G5-TAC in the G5-TAC/PIP membrane, the N1s core level spectrum was investigated by deconvolution of the narrow scan spectrum into two characteristic peaks (Figure S8b). The major peak at $400.0 \mathrm{eV}$ represents $\mathrm{N}-\mathrm{C}=\mathrm{O}$ species, which is most likely from PAMAM G5-TAC and PA matrix, while another peak at $401.5 \mathrm{eV}$ is ascribe to $\mathrm{C}-\mathrm{N}^{+}$, which only exists in PAMAM G5-TAC. ${ }^{10}$

(a)

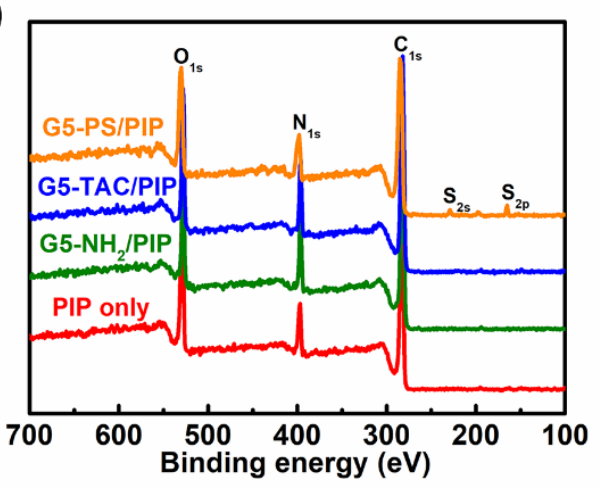

(b)

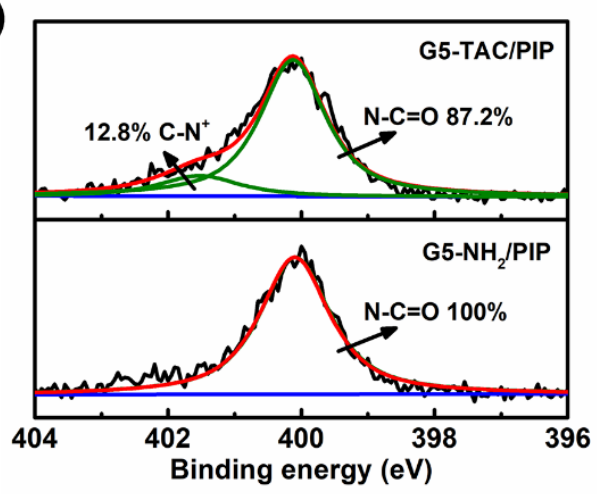

Figure S8. (a) XPS spectrum of the PA membranes; (b) $N$ 1s narrow scan spectrum and calculated percentages of chemical species from the deconvolution of $N$ 1s core level XPS spectrum of the G5-TAC/PIP membrane.

Table S3. Elemental Composition of the PA Membranes Calculated from XPS Analysis

\begin{tabular}{ccccc}
\hline \multirow{2}{*}{ Membrane } & \multicolumn{4}{c}{ Atomic Composition (\%) } \\
\cline { 2 - 5 } & $\mathrm{C}$ & $\mathrm{O}$ & $\mathrm{N}$ & $\mathrm{S}$ \\
\hline PIP only & 72.31 & 17.22 & 10.47 & - \\
G5-NH2/PIP & 74.59 & 14.79 & 10.62 & - \\
G5-TAC/PIP & 71.97 & 14.74 & 13.17 & - \\
G5-PS/PIP & 73.57 & 15.88 & 9.80 & 0.75 \\
\hline
\end{tabular}




\section{Section S7. Surface Hydrophilicity of the PA Membranes}

According to the conclusions from XPS analysis (Section S6), ionic PAMAM dendrimers along with their terminal ionizable groups were detected at the top surface of the PA membranes. Due to the much higher hydratability of quaternary ammonium and sulfonic acid groups, ${ }^{11}$ the WCAs of G5-TAC/PIP and G5-PS/PIP membranes are much lower than PIP only and G5-NH2/PIP membranes (Figure S9), which means surface hydrophilicity of the ionic PAMAM dendrimer based PA membrane surface was improved.

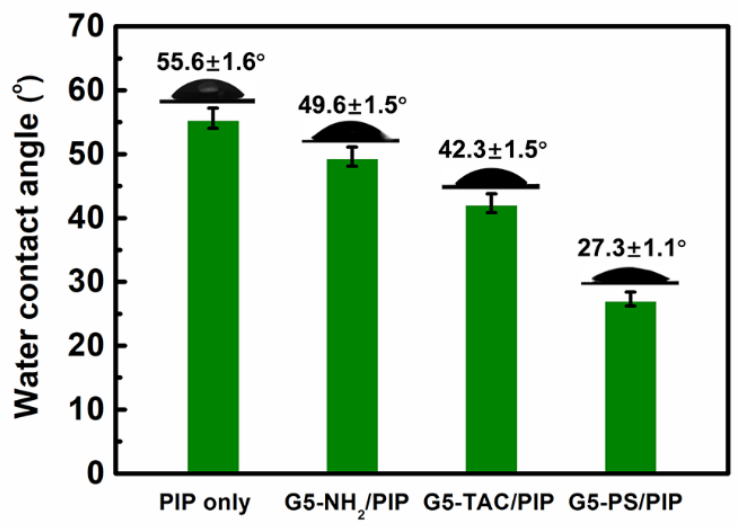

Figure S9. WCAs of the PA membrane surfaces. 


\section{Section S8. Roughness of the PA Membrane Surfaces}

Different from conventional IP reaction which contains only one kind of amine monomer in the aqueous phase solution, adding nanomaterials into the aqueous phase solution will lead to various structures of the PA membranes considering their influence on diffusion of PIP molecules from aqueous phase to organic phase (Figure S10). ${ }^{12}$ For aqueous solution consisting of mixture of PAMAM dendrimers and PIP, as the migration of PIP molecules to the aqueous/organic interface can be disturbed by PAMAM dendrimers, the top surfaces of G5-NH2/PIP, G5-TAC/PIP and G5-PS/PIP membranes are much rougher. Moreover, as the stronger mutual repulsion between terminal quaternary ammonium groups on PAMAM G5-TAC and PIP molecules, root mean square roughness (RMS) of G5-TAC/PIP membrane is larger than that of G5$\mathrm{NH}_{2}$ /PIP membrane. On the contrary, the mutual attraction between terminal sulfonic acid groups on PAMAM G5-PS and PIP molecules resulted in lower RMS of G5PS/PIP membrane. ${ }^{13,14}$
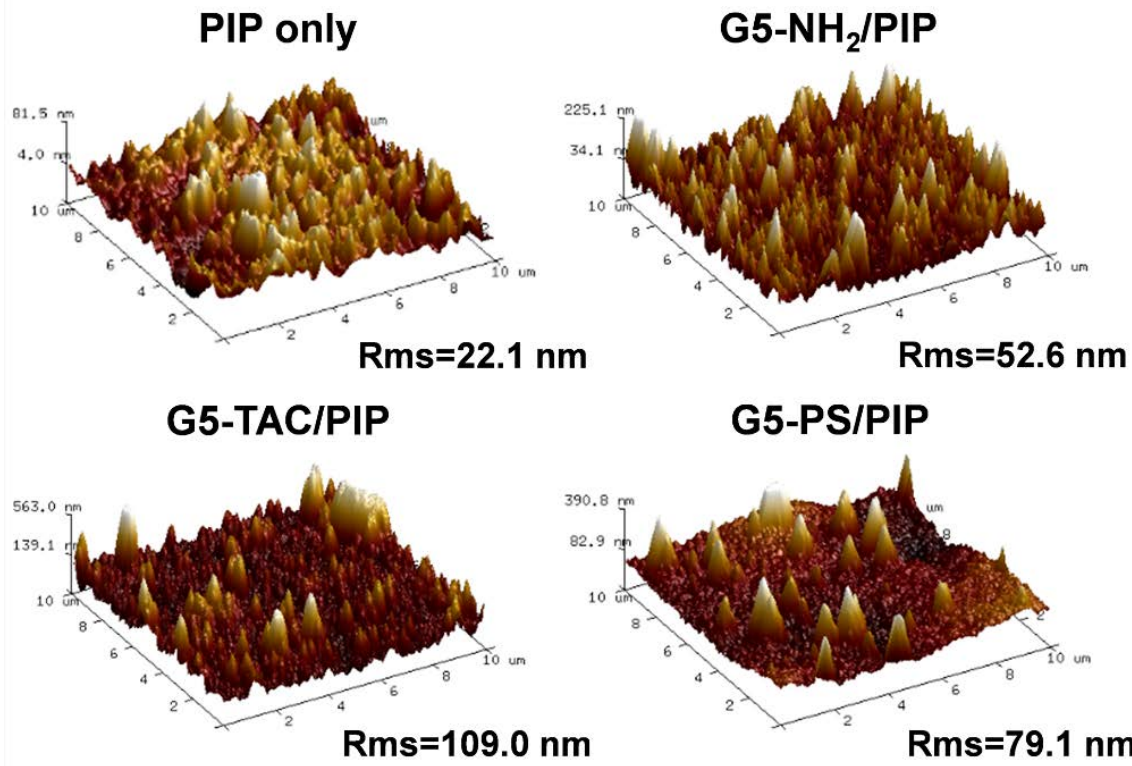

Figure S10. AFM images of the PA membranes. 


\section{Section S9. Zeta Potential of the PA Membranes}

Zeta potential of the PA membranes was measured over a $\mathrm{pH}$ value of 2-10 at ambient temperature (Figure S11). Considering of the typical PA structure, there are unreacted acyl chloride groups in PIP only membrane, which will be translated to carboxylic groups via hydrolysis reaction. ${ }^{15}$ And the deprotonation of carboxyl groups occurred under base condition, resulting in a transformation of charge property from positive charge to negative charge when $\mathrm{pH}$ value was above 5.4. Similarly, as the protonation of amine groups only occurred under acidic condition, G5- $\mathrm{NH}_{2} / \mathrm{PIP}$ membrane was positively charged when $\mathrm{pH}$ value was below 6.7. In view of the stronger protonation of quaternary ammonium groups and deprotonation of sulfonic acid groups, G5-TAC/PIP and G5-PS/PIP membranes are positively and negatively charged respectively in a wider $\mathrm{pH}$ value range. ${ }^{16}$

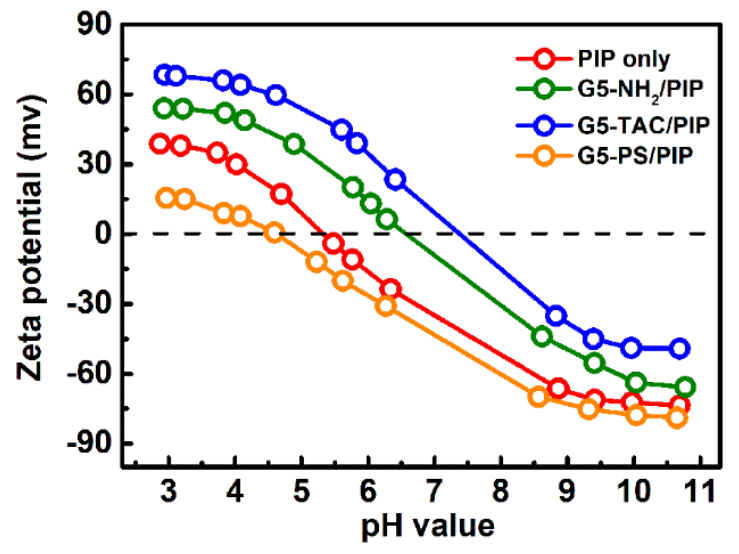

Figure S11. Zeta potential of the PA membranes. 
Section S10. Synthesis of Dendrimer-Encapsulated Gold Nanoparticles (Au DENPs)

The Au DENPs were synthesized by using PAMAM G5-NH2, PAMAM G5-TAC and PAMAM G5-PS as templates (Figure. S12a1, S12b1 and S12c1). ${ }^{17-19}$ For instance, the preparation procedure of PAMAM G5- $\mathrm{NH}_{2}(\mathrm{Au})$ was illustrated in detail. Briefly, 50 equivalents of $\mathrm{HAuCl}_{4}$ aqueous solution $(100 \mathrm{mM}, 1 \mathrm{ml})$ were mixed with PAMAM G5- $\mathrm{NH}_{2}$ aqueous solution $(0.01 \mathrm{mM}, 200 \mathrm{ml})$. The pale-yellow solution was vigorously stirred for 30 min in dark environment to make the $\mathrm{HAuCl}_{4}$ be extracted into the PAMAM G5-NH2 interior. Then a 1-fold excess of $\mathrm{NaBH}_{4}$ solution $(100 \mathrm{Mm}, 2 \mathrm{ml})$ dissolved in a water/methanol (2:1 in volume) mixture was quickly added to this solution with stirring to reduce this precursor to Au DENPs. The color of the reaction mixture immediately changed to deep-red after addition of the $\mathrm{NaBH}_{4}$ solution. The solution was stirred for at least $2 \mathrm{~h}$ to complete the reaction. The solution was filtered by using a polyether sulfone ultrafiltration (PES-UF) membrane (MWCO: 10k) in order to remove the excess reactants, followed by lyophilization to obtain the product PAMAM G5-NH2(Au) DENPs. The other two kinds of Au DENPs were synthesized by similar methods. The successful synthesis of $\mathrm{Au}$ DENPs was confirmed by ultraviolet and visible spectrophotometer (UV), as the surface plasmon resonance band of Au DENPs (510 nm) is observed (Figure S12a2, S12b2 and S12c2). TEM images show that the synthesized Au DENPs are well dispersed in water (Figure S12a4, S12b4 and S12c4) and their average diameters are all smaller than PAMAM dendrimer templates (Figure S12a3, S12b3 and S12c3), indicating that the gold nanoparticles were 
completely wrapped by PAMAM dendrimers, so that their positions in the PA selective layer can be traced.

(a1)

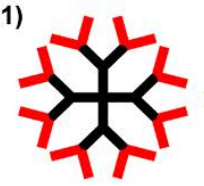

OHAuCl,

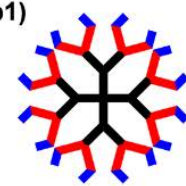

(c1)

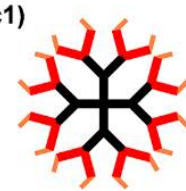

$\mathrm{OHACl}_{4}$
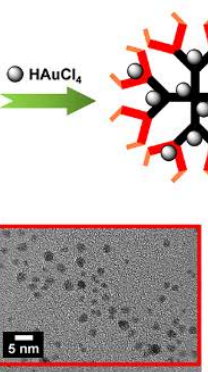

\section{(5nm}

$2 \overline{\mathrm{nm}}$

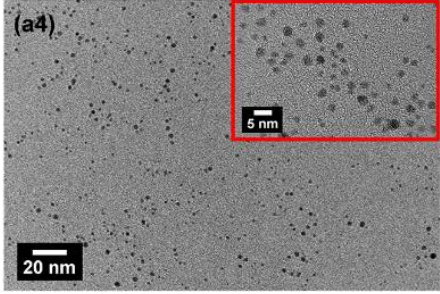

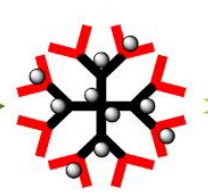
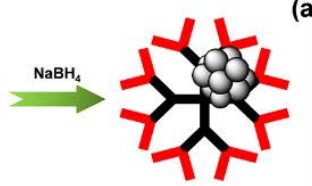

(a2) 1.8

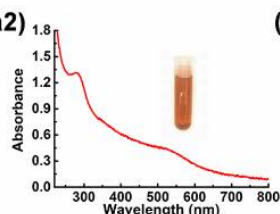

(b2)
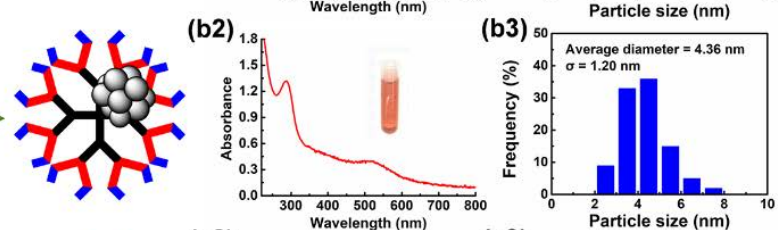

(c2)
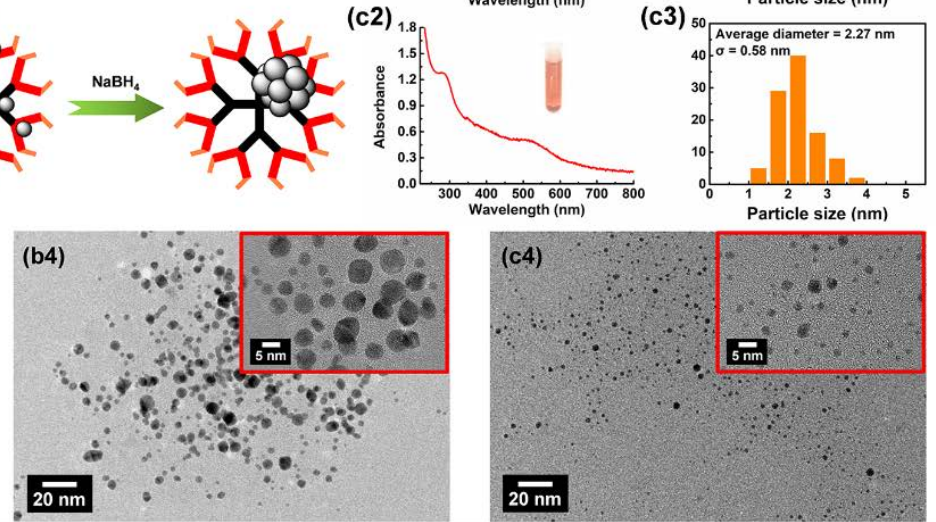

Figure S12. (a1, b1 and c1) Schematic illustration of the synthesis procedures for PAMAM G5-NH2(Au), PAMAM G5-TAC(Au) and PAMAM G5-PS(Au) respectively; (a2, b2 and c2) Ultraviolet-visible spectra of PAMAM G5- $\mathrm{NH}_{2}(\mathrm{Au})$, PAMAM G5-TAC(Au) and PAMAM G5-PS(Au) respectively (Insets of (a2, b2 and c2) are photographs of the solution of PAMAM G5-NH2(Au), PAMAM G5-TAC(Au) and PAMAM G5-PS(Au) respectively); (a3, b3 and c3) Size distribution histograms of PAMAM G5- $\mathrm{NH}_{2}(\mathrm{Au})$, PAMAM G5-TAC(Au) and PAMAM G5-PS(Au) respectively; (a4, b4 and c4) TEM images of PAMAM G5-NH2(Au), PAMAM G5TAC(Au) and PAMAM G5-PS(Au) respectively (Insets of (a4, b4 and c4) are TEM images of PAMAM G5-NH2(Au), PAMAM G5-TAC(Au) and PAMAM G5-PS(Au) with scale of 5 nm respectively). 
Section S11. Detailed Sample Preparation Procedure for Observation of Both Top and Back Surface of the Free-Standing PA Nanofilms

For example, a piece of dried PIP only membrane $(0.5 \mathrm{~cm} * 0.5 \mathrm{~cm})$ was immersed in $\mathrm{N}, \mathrm{N}$-dimethylacetylamide (DMAc) for $30 \mathrm{~min}$. After the substrate was completely removed, a transparent PA nanofilm was transferred into DI water to get rid of residual DMAc. ${ }^{20}$ Then the free-standing PA nanofilm was transferred onto a silicon wafer with top surface or back surface facing up. After $1.0 \mathrm{~h}$ drying in a vacuum oven at $50{ }^{\circ} \mathrm{C}$, the sample was taken out for FESEM imaging. Other three samples were prepared under the same procedure. 


\section{Section S12. Pore Size Calculation Procedure}

The mean effective pore size $\left(\mu_{P}\right)$ and the geometric standard deviation $\left(\sigma_{P}\right)$ of the membrane were determined by the correlation between neutral solute sizes and neutral solute rejection rates. $\mu_{P}$ is equal to the diameter of the solute at $\mathrm{R}=50 \%$, and $\sigma_{P}$ is the ratio of the solute diameter when $\mathrm{R}=84.13 \%$ over the solute diameter when $\mathrm{R}=50 \%$. Then the pore size distribution of the membrane can be expressed as shown in the following equation: ${ }^{7}$

$$
\frac{d f\left(d_{P}\right)}{d d_{P}}=\frac{1}{d_{P} \ln \sigma_{P} \sqrt{2 \pi}} \exp \left[-\frac{\left(\ln d_{P}-\ln \mu_{P}\right)^{2}}{2\left(\ln \sigma_{P}\right)^{2}}\right]
$$

where $d_{p}$ is the effective pore size of the membrane.

Pore size cut-off is a state that the sizes of above $90 \%$ of the pores are less than it. 


\section{Section S13. DSPM-DE Model to Determine Structural Parameters of the PA}

\section{Membranes}

The first step in the determination of PA membrane parameters involves the determination of effective pore size $\left(d_{p}\right)$, which was obtained from the experimental rejection of neutral solutes following the approach presented by Bowen et al. ${ }^{21}$ For simplicity, the normal definition for the real rejection of neutral solutes can be written as:

$$
R_{\text {real }}=1-\frac{C_{i, p}}{C_{i, w}}=1-\frac{K_{i, c} \emptyset}{1-\left[1-K_{i, c} \varnothing\right] \exp (-P e)}
$$

where concentration polarization was taken into account by using the permeate concentration outside the outlet of the nanochannels $\left(C_{i, p},\left(\mathrm{~mol} \mathrm{~m}^{-3}\right)\right)$ and feed concentration outside the inlet of the nanochannels $\left(C_{i, w},\left(\mathrm{~mol} \mathrm{~m}^{-3}\right)\right)$ to calculate the real rejection. $C_{i, w}$ can be represented by the following expression: ${ }^{22}$

$$
\frac{C_{i, w}-C_{i, p}}{C_{i, b}-C_{i, p}}=\exp \left(\frac{V}{k}\right)
$$

in which $k$ is the solute mass transfer coefficient relating to the filtration cell $\left(\mathrm{m} \mathrm{s}^{-1}\right)$, $C_{i, b}$ is bulk solution concentration of ion $i\left(\mathrm{~mol} \mathrm{~m}^{-3}\right), V$ is permeate flux $\left(\mathrm{m}^{3} \mathrm{~h}^{-1}\right) ; K_{i, c}$ is hindrance factor for convection of neutral solute, $\varnothing$ is uncharged solute steric partitioning coefficient, which is equal to $(1-\lambda)^{2}, \lambda$ is expressed in terms of the ratio of the solute Stokes diameter to the effective pore size, $P e$ is the Péclet number that are calculated according to:

$$
P e=\frac{K_{i, c} d_{p}^{2} \Delta P_{e}}{32 K_{i, d} D_{i, \infty} \eta_{0}}
$$

Where $\Delta P_{e}$ is effective pressure $\left(\mathrm{N} \mathrm{m}^{-2}\right)$, which is equal to the difference between applied pressure $(\Delta P)$ and dynamic osmotic pressure $(\Delta \pi)$, while $\Delta \pi$ can be 
calculated by the equation of $\Delta \pi=R T\left[\sum C_{i, w}-\sum C_{i, p}\right], R$ is universal gas constant (8.314 $\mathrm{J} \mathrm{mol}^{-1} \mathrm{~K}^{-1}$ ), $T$ is absolute temperature $(\mathrm{K}), K_{i, d}$ is hindrance factor for diffusion of neutral solute, $D_{i, \infty}$ is bulk diffusion coefficient of neutral solute $\left(\mathrm{m}^{2} \mathrm{~s}^{-1}\right)$, $\eta_{0}$ is bulk solvent viscosity $\left(0.000894 \mathrm{~N} \mathrm{~s} \mathrm{~m}^{-2}\right)$.

The results obtained from running neutral solute (glycerol, glucose and sucrose) experiments under the effective pressure ranging from $0.1 \mathrm{MPa}$ to $0.5 \mathrm{MPa}$, along with model fitting from the experiment data are shown in Figure S13. With these results, effective pore sizes calculated from each fitted curve of neutral solute are listed in Table S4.

(a)

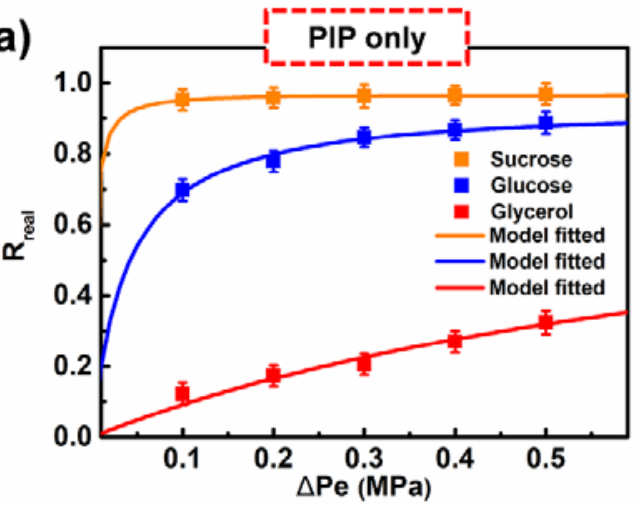

(c)

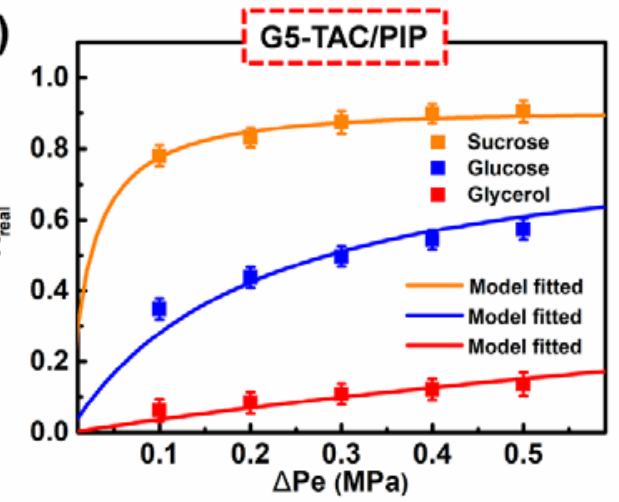

(b)

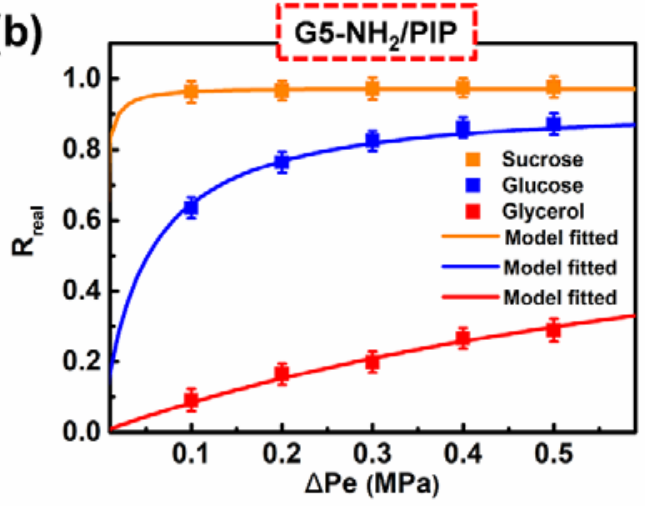

(d)

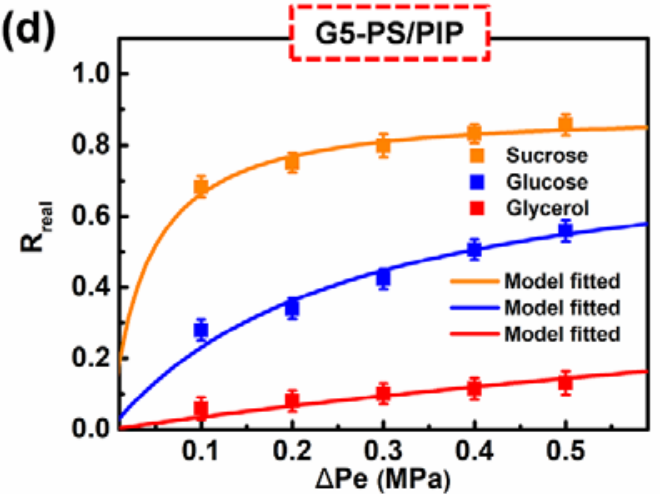

Figure S13. Variation of experimental neutral solute rejection with effective pressure and model fits from the experimental data for the (a) PIP only, (b) G5-NH2/PIP, (c) G5-TAC/PIP and (d) G5-PS/PIP membranes to obtain the effective pore size (Concentration of each neutral solute was $\left.0.2 \mathrm{~g} \mathrm{~L}^{-1}\right)$. 
Table S4 Fitting Results for the Pore Sizes of the PA Membranes

\begin{tabular}{|c|c|c|c|c|c|}
\hline \multirow{2}{*}{ Solute } & \multicolumn{2}{|c|}{ PIP only } & \multirow{2}{*}{ Solute } & \multicolumn{2}{|c|}{ G5- $\mathrm{NH}_{2}$} \\
\hline & $d_{p}(\mathrm{~nm})$ & $S_{y}$ & & $d_{p}(\mathrm{~nm})$ & $S_{y}$ \\
\hline Gly & 0.924 & 0.019 & Gly & 0.942 & 0.011 \\
\hline Glu & 0.984 & 0.012 & Glu & 1.002 & 0.012 \\
\hline Suc & 1.134 & 0.003 & Suc & 1.112 & 0.004 \\
\hline Overall & 1.014 & 0.012 & Overall & 1.018 & 0.009 \\
\hline \multirow{2}{*}{ Solute } & \multicolumn{2}{|c|}{ G5-TAC } & \multirow{2}{*}{ Solute } & \multicolumn{2}{|c|}{ G5-PS } \\
\hline & $d_{p}(\mathrm{~nm})$ & $S_{y}$ & & $d_{p}(\mathrm{~nm})$ & $S_{y}$ \\
\hline Gly & 1.178 & 0.017 & Gly & 1.204 & 0.030 \\
\hline Glu & 1.212 & 0.041 & Glu & 1.268 & 0.030 \\
\hline Suc & 1.296 & 0.012 & Suc & 1.378 & 0.016 \\
\hline Overall & 1.230 & 0.025 & Overall & 1.284 & 0.024 \\
\hline
\end{tabular}

Electrochemical studies of colloidal systems have shown the presence of one layer of water molecules at the colloid-solvent interface with a dielectric constant which is significantly smaller than bulk water. ${ }^{21,23}$ Orientation of the water molecules at pore walls will lead to a reduction of dielectric constant. To facilitate model development, the solvent within the pores is assumed to consist of one layer of oriented water molecules with a dielectric constant $\left(\varepsilon^{*}\right)$ and an inner part with bulk dielectric properties. The variation of average pore dielectric constant $\left(\varepsilon_{p}\right)$ can be calculated on a geometric basis (assuming bulk dielectric constant of water $\left(\varepsilon_{b}\right)$ to 80 ):

$$
\varepsilon_{p}=80-2\left(80-\varepsilon^{*}\right)\left(\frac{d}{r_{p}}\right)+\left(80-\varepsilon^{*}\right)\left(\frac{d}{r_{p}}\right)^{2}
$$

where $d$ is thickness of the oriented solvent layer $(0.28 \mathrm{~nm}), r_{p}$ is effective pore radius (m).

To assess the average pore dielectric constant, rejection of $0.1 \mathrm{M} \mathrm{NaCl}$ aqueous solution as a function of effective pressure is used (Donnan effect was completely screened in this case). along with model fitting from the experiment data are shown in 
Figure S14.
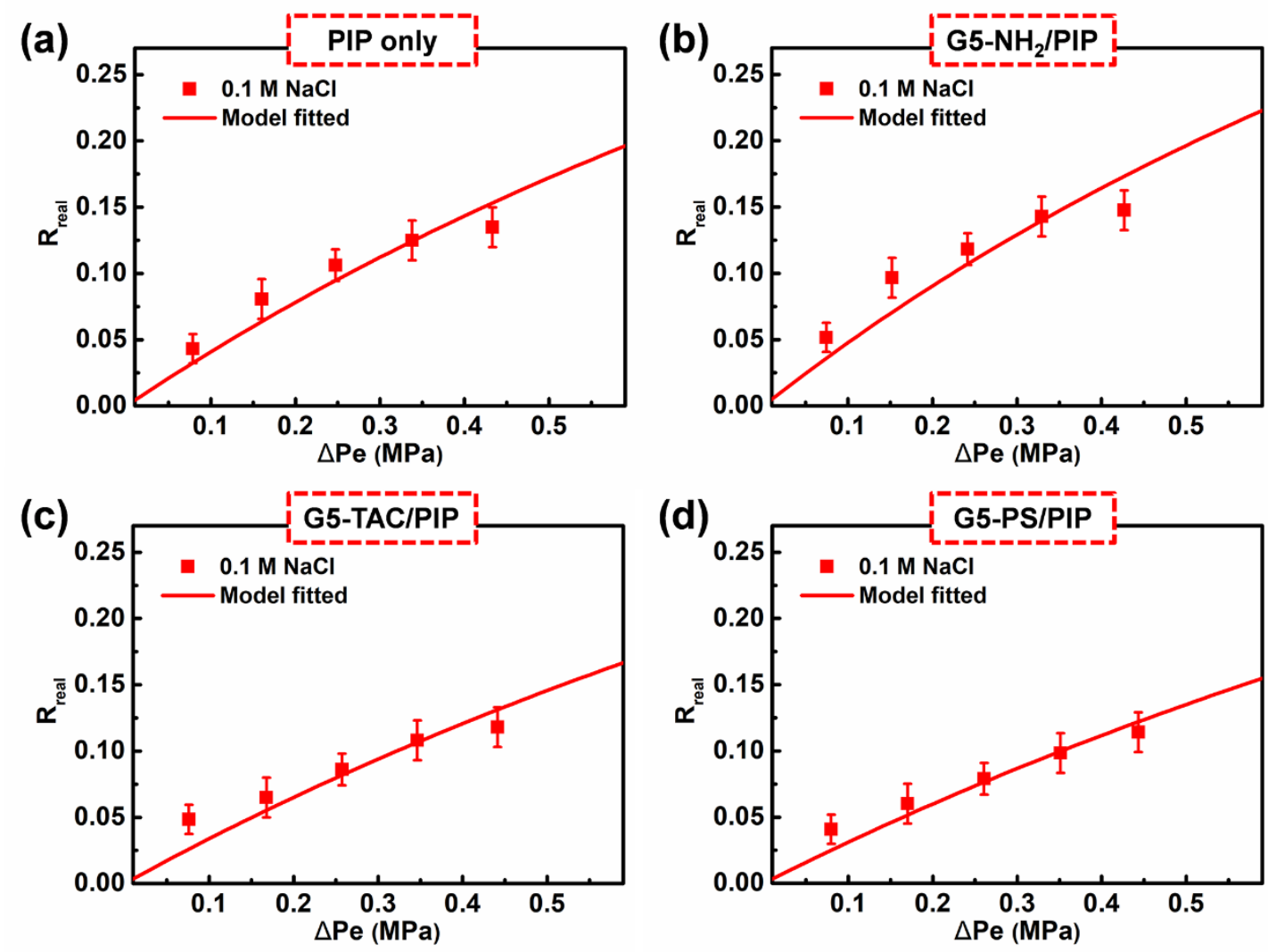

Figure S14. Variation of experimental $\mathrm{NaCl}$ rejection with effective pressure and model fits from the experimental data for the (a) PIP only, (b) G5-NH2/PIP, (c) G5-TAC/PIP and (d) G5PS/PIP membranes to obtain the pore dielectric constant (Concentration of $\mathrm{NaCl}$ was $0.1 \mathrm{M}$ ).

$0.01 \mathrm{M}$ electrolyte aqueous solution including $\mathrm{Na}_{2} \mathrm{SO}_{4}, \mathrm{MgSO}_{4}, \mathrm{MgCl}_{2}$, or $\mathrm{NaCl}$ was used to investigate the charging properties of the membrane through evaluation of membrane charge density $\left(X_{d}\right)$ based on the extended Nerst-Planck equation, along with solute partitioning under electrochemical equilibrium. Variation of experimental salt rejection with effective pressure and model fits from the experimental data for the PA membranes are shown in Figure S15. 

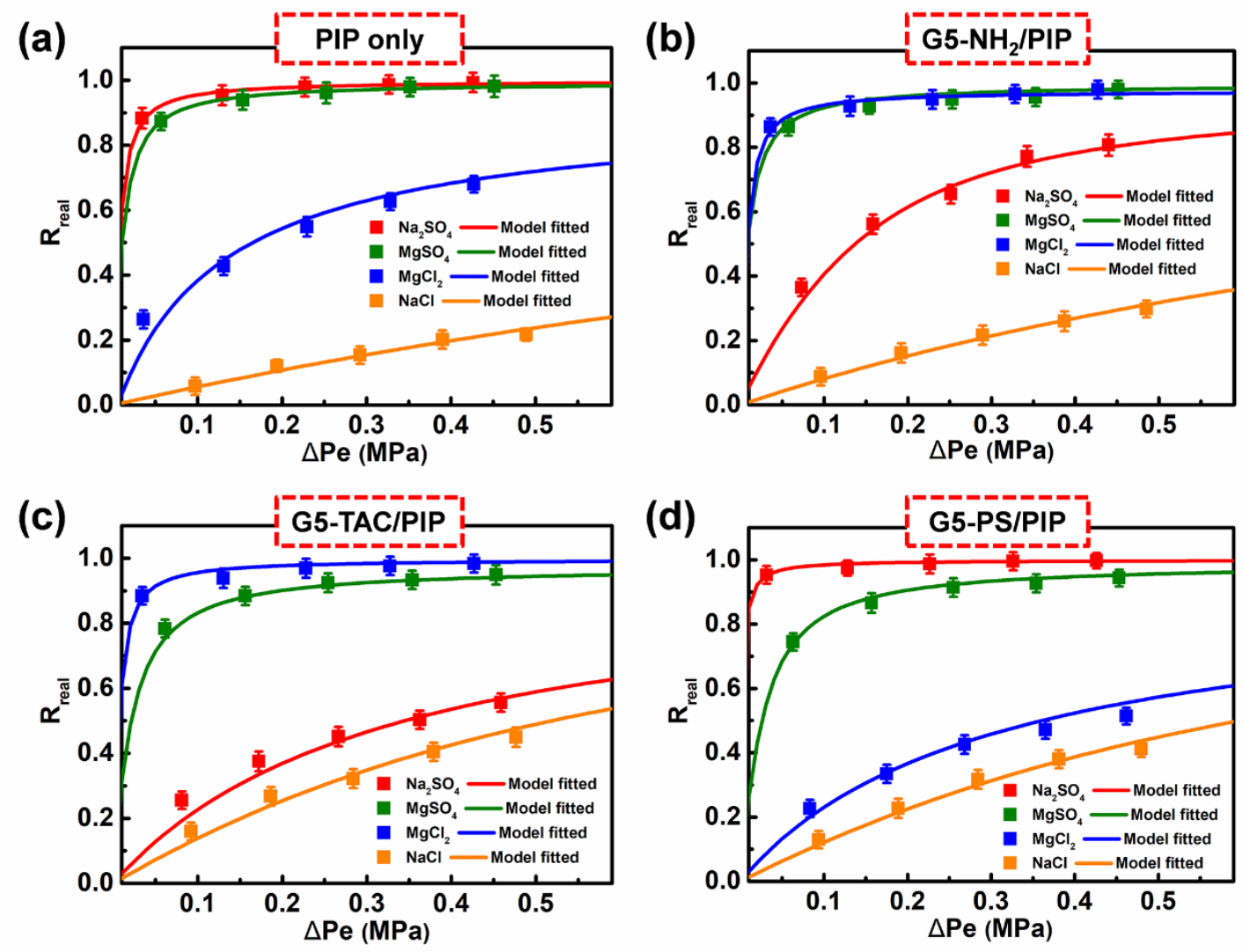

Figure S15. Variation of experimental salt rejection with effective pressure and model fits from the experimental data for the (a) PIP only, (b) G5-NH2/PIP, (c) G5-TAC/PIP and (d) G5-PS/PIP membranes to obtain the membrane charge density (Concentration of each salt was $0.01 \mathrm{M}$ ). 
Section S14. Comparison of Single Salt Selectivities of Lab Prepared Membranes

Reported in Literatures, Commercially Available Membranes and the Ionic PAMAM Dendrimer Based PA Membranes.

Table S5. Comparison of Single Salt Selectivity ( $\mathrm{NaCl}$ to $\left.\mathrm{MgCl}_{2}\right)$ of G5-TAC/PIP

Membrane with Lab Prepared Membranes Reported in Literatures and Commercially Available Membranes

\begin{tabular}{|c|c|c|c|c|c|}
\hline \multirow{2}{*}{ Membrane } & \multirow{2}{*}{$\begin{array}{l}\text { Water permeance } \\
\left(\mathrm{L} \mathrm{m}^{-2} \mathrm{~h}^{-1} \mathrm{MPa}^{-1}\right)\end{array}$} & \multicolumn{2}{|c|}{ Salt rejection (\%) } & \multirow{2}{*}{$\begin{array}{l}\text { Single salt selectivity } \\
\qquad\left(\mathrm{NaCl} \text { to } \mathrm{MgCl}_{2}\right)\end{array}$} & \multirow{2}{*}{ Ref. } \\
\hline & & $\mathrm{MgCl}_{2}$ & $\mathrm{NaCl}$ & & \\
\hline G5-TAC/PIP & 142 & 97.0 & 37.2 & 20.9 & This work \\
\hline CS & 16 & 94.8 & 29.8 & 13.5 & 24 \\
\hline $\mathrm{MoS}_{2} / \mathrm{PEI}$ & 46 & 95.5 & 59.9 & 8.9 & 25 \\
\hline M-PEI & 51 & 95.9 & 30.3 & 17.0 & 26 \\
\hline $\mathrm{PVI} / \mathrm{PSF}$ & 55 & 90.1 & 54.0 & 4.6 & 27 \\
\hline $\begin{array}{c}{[\operatorname{MimAP}]\left[\mathrm{Tf}_{2} \mathrm{~N}\right]-} \\
\text { PA/PAN }\end{array}$ & 63 & 83.8 & 30.1 & 4.3 & 28 \\
\hline PEI-Dex/PEI & 74 & 86.0 & 36.0 & 4.6 & 29 \\
\hline TFC-SDS & 75 & 94.2 & 47.1 & 8.8 & 30 \\
\hline PVC-g-PDMA & 93 & 93.1 & 70.3 & 4.3 & 31 \\
\hline $\begin{array}{c}\text { (PES- } \\
\text { GO)/PEI/TMC }\end{array}$ & 112 & 95.1 & 21.1 & 16.1 & 32 \\
\hline $\begin{array}{c}\text { PEI/PDA- } \\
\text { MWCNTs/TMC }\end{array}$ & 153 & 91.5 & 35.4 & 7.6 & 33 \\
\hline $\begin{array}{l}\text { PEI-grafted- } \\
\text { MWCNT }\end{array}$ & 165 & 95.0 & 25.0 & 15 & 34 \\
\hline PEI/PIP/TMC & 167 & 95.2 & 50.6 & 10.3 & 35 \\
\hline PDA/PEI/NCMs & 170 & 90.0 & 30 & 7 & 36 \\
\hline PEI/PIP & 182 & 96.3 & 53.6 & 12.5 & 37 \\
\hline PEI/TMA & 192 & 90.2 & 53.9 & 4.7 & 38 \\
\hline $\begin{array}{c}\text { Py-PDEAEMA/GO } \\
\text { NFMs }\end{array}$ & 220 & 46.0 & 32.0 & 1.2 & 39 \\
\hline ED-TFN & 246 & 90.7 & 40.5 & 6.4 & 40 \\
\hline PSF-G4D-1 & 259 & 80.0 & 41.1 & 2.9 & 41 \\
\hline SWCNT-PA & 400 & 64.9 & 13.4 & 2.5 & 42 \\
\hline PA-1/MCE & 840 & 52.8 & 13.7 & 1.8 & 43 \\
\hline ESNA 1 & 75 & 89.0 & 93.0 & 0.6 & 37 \\
\hline UTC-20 & 102 & 98.0 & 55.0 & 22.5 & 37 \\
\hline NF 40 & 22 & 70.0 & 45.0 & 1.8 & 44 \\
\hline
\end{tabular}




\begin{tabular}{cccccc}
\hline NTR-7450 & 109 & 16.0 & 53.0 & 0.6 & 37 \\
NF 270 & 132 & 60.0 & 51.0 & 1.2 & 37 \\
NF 90 & 83 & 99.2 & 87.6 & 15.5 & 45 \\
\hline
\end{tabular}

Table S6. Comparison of Single Salt Selectivity ( $\mathrm{NaCl}$ to $\left.\mathrm{Na}_{2} \mathrm{SO}_{4}\right)$ of G5-PS/PIP

Membrane with Lab Prepared Membranes Reported in Literatures and Commercially Available Membranes

\begin{tabular}{|c|c|c|c|c|c|}
\hline \multirow{2}{*}{ Membrane } & \multirow{2}{*}{$\begin{array}{l}\text { Water permeance } \\
\left(\mathrm{L} \mathrm{m}^{-2} \mathrm{~h}^{-1} \mathrm{MPa}^{-1}\right)\end{array}$} & \multicolumn{2}{|c|}{ Salt rejection (\%) } & \multirow{2}{*}{$\begin{array}{l}\text { Single salt selectivity } \\
\qquad\left(\mathrm{NaCl} \text { to } \mathrm{Na}_{2} \mathrm{SO}_{4}\right)\end{array}$} & \multirow{2}{*}{ Ref. } \\
\hline & & $\mathrm{Na}_{2} \mathrm{SO}_{4}$ & $\mathrm{NaCl}$ & & \\
\hline G5-PS/PIP & 173 & 99.5 & 34.5 & 131.0 & This work \\
\hline PA-PPTA/Psf 8 & 85 & 99.1 & 63.6 & 40.4 & 46 \\
\hline BTC-PIP & 87 & 99.1 & 83.3 & 18.6 & 47 \\
\hline TFNM with $\mathrm{HZN}_{\mathrm{c}} \mathrm{S}$ & 122 & 94.7 & 38.2 & 11.7 & 48 \\
\hline CNC-TFC & 165 & 98.7 & 22.7 & 59.5 & 49 \\
\hline PES-CNT-PA & 210 & 98.5 & 18.8 & 54.1 & 50 \\
\hline PVA hydrogel-TFC & 528 & 96.4 & 20.0 & 22.2 & 51 \\
\hline TS-II & 248 & 99.6 & 49.6 & 126.0 & 12 \\
\hline $\mathrm{PA} / \mathrm{PAN}-\mathrm{NaCl}$ & 258 & 99.1 & 26.1 & 82.1 & 52 \\
\hline Noria-PEI & 280 & 96.0 & 50.0 & 12.5 & 53 \\
\hline TFN-AU & 308 & 97.5 & 20.3 & 31.9 & 54 \\
\hline PES-COF-PA & 311 & 95.0 & 12.0 & 17.6 & 55 \\
\hline $\mathrm{PA} / \mathrm{GE} / \mathrm{PAN}$ & 337 & 98.1 & 14.0 & 45.3 & 56 \\
\hline SWCNT-PA & 400 & 96.5 & 13.6 & 24.7 & 42 \\
\hline TpTG $\mathrm{Cl}_{1} @ \mathrm{CNFs} / \mathrm{PAN}$ & 428 & 96.8 & 23.8 & 23.8 & 57 \\
\hline THPC-TFCM & 505 & 98.4 & 23.2 & 48 & 58 \\
\hline PA/CLS & 533 & 94.3 & 27.0 & 12.8 & 59 \\
\hline PD/ZIF-8/PA & 535 & 95.3 & 11.2 & 18.9 & 60 \\
\hline $\mathrm{TFC}_{60}$ & 106 & 96.2 & 21.1 & 20.8 & 61 \\
\hline $\mathrm{TFN}_{\mathrm{PDA} \text {-SINPS }}$ & 133 & 97.0 & 35.0 & 21.7 & 62 \\
\hline PA-1/MCE & 840 & 99.0 & 13.7 & 86.1 & 43 \\
\hline NTR-7250 & 63 & 99.0 & 55.0 & 25 & 63 \\
\hline NF 270 & 132 & 98.0 & 51.0 & 24.5 & 37 \\
\hline NF 40 & 22 & 95.0 & 45.0 & 11 & 44 \\
\hline UTC-20 & 102 & 93.0 & 55.0 & 6.4 & 37 \\
\hline NTR-7450 & 109 & 92.0 & 53.0 & 5.9 & 37 \\
\hline NS300 & 35 & 97.8 & 70.0 & 13.6 & 64 \\
\hline
\end{tabular}




\section{Section S15. Separation of Low/High Valent Co-Ions with Different Feed Solution}

\section{Concentrations}

Separation performance of the PA membranes to low/high valent co-ions was tested by feed solutions with different concentrations. With the concentration of $\mathrm{NaCl} / \mathrm{MgCl}_{2}$ and $\mathrm{NaCl} / \mathrm{Na}_{2} \mathrm{SO}_{4}$ binary salt mixture solutions increasing from 0.5 to 10.0 $\mathrm{g} \mathrm{L}^{-1}$ (both mass concentration ratios of $\mathrm{NaCl}$ to $\mathrm{MgCl}_{2}$ and $\mathrm{NaCl}$ to $\mathrm{Na}_{2} \mathrm{SO}_{4}$ were fixed at 1:1), the charge screening effect will lead to lower membrane charge densities and thus weaker electrostatic repulsion for ions. So the transport of ions through the charged nanochannels is easier, resulting in declines of $\mathrm{Na}^{+} / \mathrm{Mg}^{2+}$ or $\mathrm{Cl} / \mathrm{SO}_{4}{ }^{2-}$ selectivity of the PA membranes (Figure S16). Meanwhile, with an increase of ionic strength and osmotic pressure, permeate fluxes of the PA membranes decrease obviously. It is worth noting that contributed by their lower sensitivities to membrane charge densities, G5-TAC/PIP and G5-PS/PIP membranes exhibit much higher selectivity to low/high valent co-ions in feed solutions with high concentration, compared to G5-NH2/PIP and PIP only membranes respectively. 
(a)

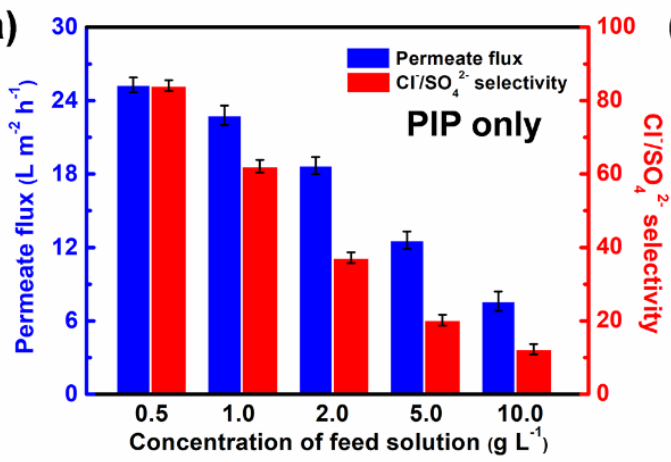

(c)

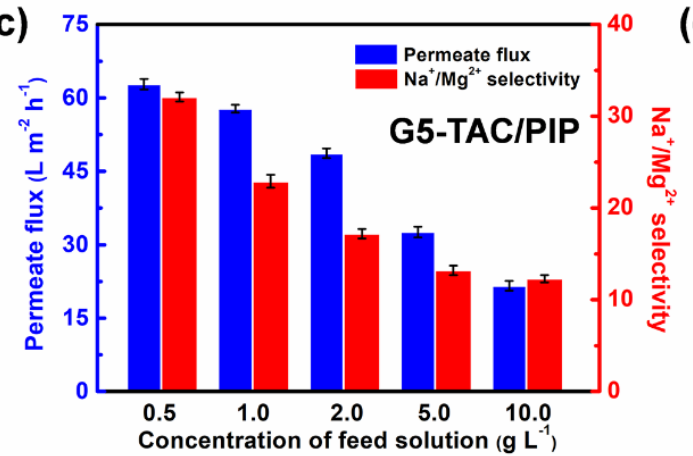

(b)

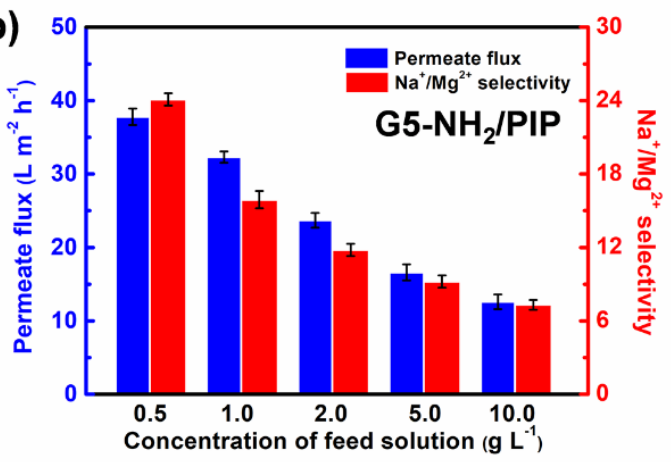

(d)

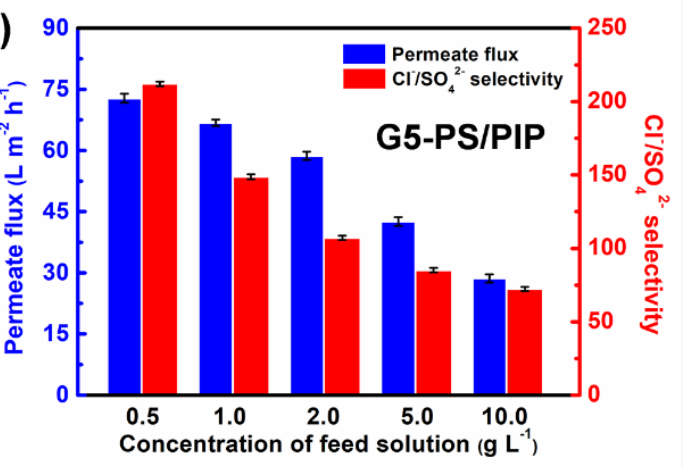

Figure S16. (a) Permeate flux and $\mathrm{Cl}^{2} / \mathrm{SO}_{4}{ }^{2-}$ selectivity of the PIP only membrane with the concentration of feed solution ranging from 0.5 to $10.0 \mathrm{~g} \mathrm{~L}^{-1}$ (mass concentration ratio of $\mathrm{NaCl}$ to $\mathrm{Na}_{2} \mathrm{SO}_{4}$ was fixed at 1:1); (b) Permeate flux and $\mathrm{Na}^{+} / \mathrm{Mg}^{2+}$ selectivity of the G5- $\mathrm{NH}_{2} / \mathrm{PIP}$ membrane with the concentration of feed solution ranging from 0.5 to $10.0 \mathrm{~g} \mathrm{~L}^{-1}$ (mass concentration ratio of $\mathrm{NaCl}$ to $\mathrm{MgCl}_{2}$ was fixed at 1:1); (c) Permeate flux and $\mathrm{Na}^{+} / \mathrm{Mg}^{2+}$ selectivity of the G5-TAC/PIP membrane with the concentration of feed solution ranging from 0.5 to $10.0 \mathrm{~g} \mathrm{~L}^{-1}$ (mass concentration ratio of $\mathrm{NaCl}$ to $\mathrm{MgCl}_{2}$ was fixed at 1:1); (d) Permeate flux and $\mathrm{Cl} / \mathrm{SO}_{4}{ }^{2-}$ selectivity of the G5-PS/PIP membrane with the concentration of feed solution ranging from 0.5 to $10.0 \mathrm{~g} \mathrm{~L}^{-1}$ (mass concentration ratio of $\mathrm{NaCl}$ to $\mathrm{Na}_{2} \mathrm{SO}_{4}$ was fixed at 1:1). 


\section{Section S16. Stability Test of the Ionic PA Membranes}

Stability is a very important problem to be solved in practical application due to the dissolution of embedded nanomaterials. Thus, backwashing test was designed to evaluate the bonding strength between ionic PAMAM dendrimers and PA matrix. ${ }^{7}$ It is worth noting that the $\mathrm{MgCl}_{2}$ rejection rate and permeate flux of G5-TAC/PIP membrane as well as the $\mathrm{Na}_{2} \mathrm{SO}_{4}$ rejection rate and permeate flux of G5-PS/PIP membrane remain almost unchanged after 30 min backwashing treatment at $0.1 \mathrm{MPa}$ (Figure S17a and S17c). With an increase of backwashing pressure, both the $\mathrm{MgCl}_{2}$ and $\mathrm{Na}_{2} \mathrm{SO}_{4}$ rejection rates decrease gradually while their permeate fluxes are almost constant. Even when the backwashing pressure reaches $0.5 \mathrm{MPa}$, the rejection rate of the G5-TAC/PIP membrane to $\mathrm{MgCl}_{2}$ is still above $90 \%$ and the rejection rate of the G5-PS/PIP membrane to $\mathrm{Na}_{2} \mathrm{SO}_{4}$ is still above $95 \%$, indicating the firm combination between ionic PAMAM dendrimers and PA matrix.

Long-term stability is another important property of ionic PAMAM dendrimer based PA membranes which should be examined. The test was conducted at $0.4 \mathrm{MPa}$ and the samples were collected every $12 \mathrm{~h}$. It is obvious that the $\mathrm{MgCl}_{2}$ rejection rate and permeate flux of the G5-TAC/PIP membrane as well as $\mathrm{Na}_{2} \mathrm{SO}_{4}$ rejection rate and permeate flux of the G5-PS/PIP membrane fluctuated slightly during the continuous 120 h filtration, suggesting the good long-term stability of ionic PAMAM dendrimer based PA membranes (Figure S17b and S17d). 

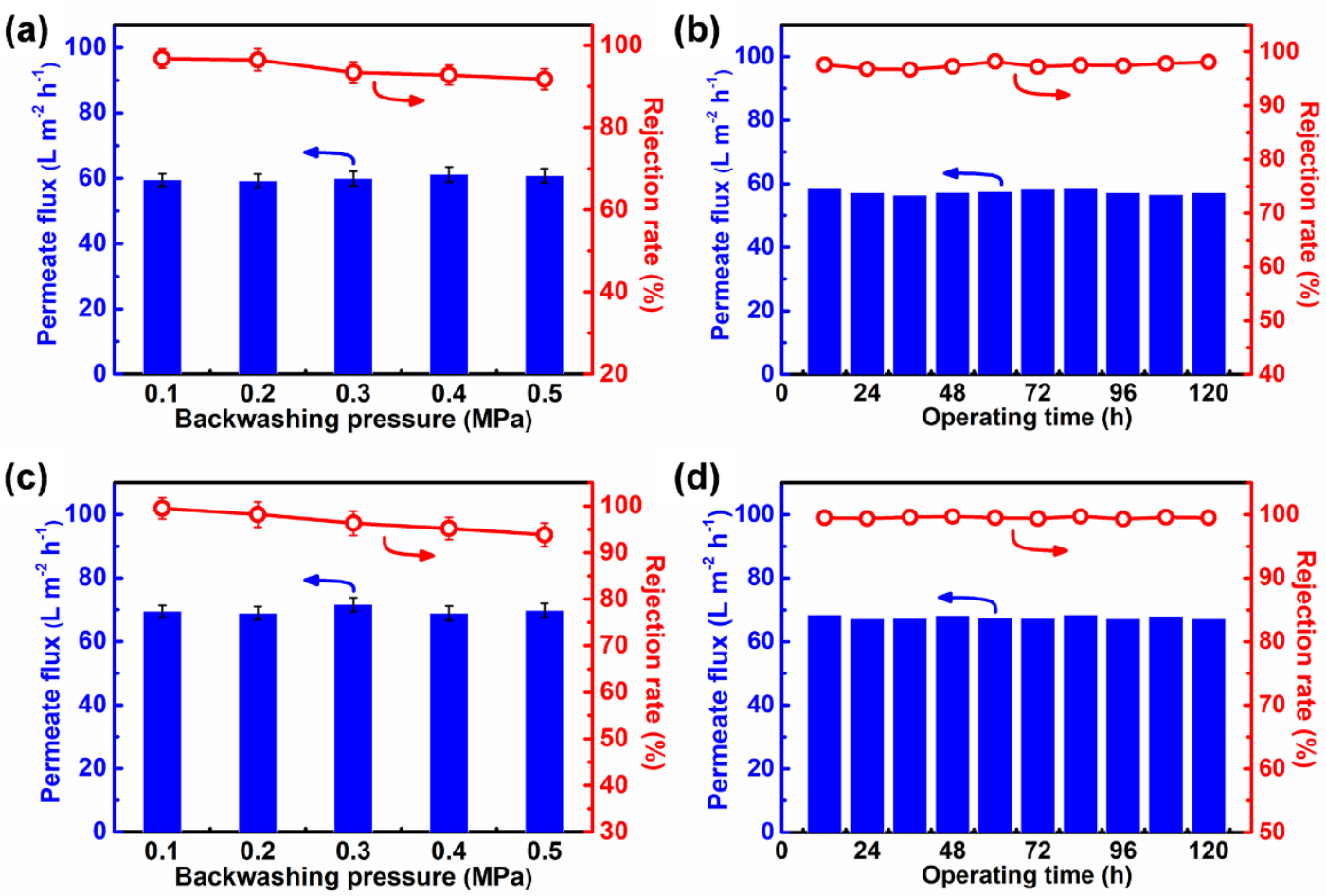

Figure S17. (a) Variations of $\mathrm{MgCl}_{2}$ rejection and permeate flux of G5-TAC/PIP membrane after backwashing for $30 \mathrm{~min}$ under different pressure; (b) Variations of $\mathrm{MgCl}_{2}$ rejection and permeate flux of G5-TAC/PIP membrane during 120 h continuous filtration; (c) Variations of $\mathrm{Na}_{2} \mathrm{SO}_{4}$ rejection and permeate flux of G5-PS/PIP membrane after backwashing for $30 \mathrm{~min}$ under different pressure; (d) Variations of $\mathrm{Na}_{2} \mathrm{SO}_{4}$ rejection and permeate flux of G5-PS/PIP membrane during 120 h continuous filtration. 


\section{References}

1. Tomalia, D. A. Birth of a New Macromolecular Architecture: Dendrimers as Quantized Building Blocks for Nanoscale Synthetic Polymer Chemistry. Prog. Polym. Sci. 2005, 30, 294-324.

2. Singh, A. K.; Prakash, S.; Kulshrestha, V.; Shahi, V. K. Cross-Linked Hybrid Nanofiltration Membrane with Antibiofouling Properties and Self-Assembled Layered Morphology. ACS Appl. Mater. Interfaces 2012, 4, 1683-1692.

3. Han, Q.; Chen, X.; Niu, Y.; Zhao, B.; Wang, B.; Mao, C.; Chen, L.; Shen, J. Preparation of Water-Soluble Hyperbranched Polyester Nanoparticles with Sulfonic Acid Functional Groups and Their Micelles Behavior, Anticoagulant Effect and Cytotoxicity. Langmuir 2013, 29, 8402-8409.

4. Maiti, P. K.; Çağın, T.; Lin, S.-T.; Goddard, W. A. Effect of Solvent and pH on the Structure of PAMAM Dendrimers. Macromolecules 2005, 38, 979-991.

5. Tang, Y.-J.; Xu, Z.-L.; Huang, B.-Q.; Wei, Y.-M.; Yang, H. Novel Polyamide ThinFilm Composite Nanofiltration Membrane Modified with Poly(amidoamine) and $\mathrm{SiO}_{2}$ Gel. RSC Adv. 2016, 6, 45585-45594.

6. Bass, M.; Freger, V. Facile Evaluation of Coating Thickness on Membranes Using ATR-FTIR. J. Membr. Sci. 2015, 492, 348-354.

7. Kong, X.; Zhou, M.-Y.; Lin, C.-E.; Wang, J.; Zhao, B.; Wei, X.-Z.; Zhu, B.-K. Polyamide/PVC Based Composite Hollow Fiber Nanofiltration Membranes: Effect of Substrate on Properties and Performance. J. Membr. Sci. 2016, 505, 231-240.

8. Li, M.; Lv, Z.; Zheng, J.; Hu, J.; Jiang, C.; Ueda, M.; Zhang, X.; Wang, L. Positively Charged Nanofiltration Membrane with Dendritic Surface for Toxic Element 
Removal. ACS Sustainable Chem. Eng. 2016, 5, 784-792.

9. Kong, X.; Qiu, Z.-L.; Lin, C.-E.; Song, Y.-Z.; Zhu, B.-K.; Zhu, L.-P.; Wei, X.-Z. High Permselectivity Hyperbranched Polyester/Polyamide Ultrathin Films with Nanoscale Heterogeneity. J. Mater. Chem. A 2017, 5, 7876-7884.

10. Lin, C.-E.; Fang, L.-F.; Du, S.-Y.; Yao, Z.-K.; Zhu, B.-K. A Novel Positively Charged Nanofiltration Membrane Formed via Simultaneous CrossLinking/Quaternization of Poly(m-Phenylene Isophthalamide)/Polyethyleneimine Blend Membrane. Sep. Purif. Technol. 2019, 212, 101-109.

11. Shi, C.; Yan, B.; Xie, L.; Zhang, L.; Wang, J.; Takahara, A.; Zeng, H. Long-Range Hydrophilic Attraction between Water and Polyelectrolyte Surfaces in Oil. Angew. Chem. Int. Ed. 2016, 55 (48), 15017-15021.

12. Tan, Z.; Chen, S.; Peng, X.; Zhang, L.; Gao, C. Polyamide Membranes with Nanoscale Turing Structures for Water Purification. Science 2018, 360, 518-521.

13. Ji, Y.-L.; An, Q.-F.; Guo, Y.-S.; Hung, W.-S.; Lee, K.-R.; Gao, C.-J. Bio-Inspired Fabrication of High Perm-Selectivity and Anti-Fouling Membranes Based on Zwitterionic Polyelectrolyte Nanoparticles. J. Mater. Chem. A 2016, 4, 4224-4231.

14. Xiang, J.; Xie, Z.; Hoang, M.; Ng, D.; Zhang, K. Effect of Ammonium Salts on the Properties of Poly(piperazineamide) Thin Film Composite Nanofiltration Membrane. $J$. Membr. Sci. 2014, 465, 34-40.

15. Mo, Y.; Tiraferri, A.; Yip, N. Y.; Adout, A.; Huang, X.; Elimelech, M. Improved Antifouling Properties of Polyamide Nanofiltration Membranes by Reducing the Density of Surface Carboxyl Groups. Environ. Sci. Technol. 2012, 46, 13253-13261. 
16. Zhang, M.; Guan, K.; Ji, Y.; Liu, G.; Jin, W.; Xu, N. Controllable Ion Transport by Surface-Charged Graphene Oxide Membrane. Nat. Commun. 2019, 10, 1253.

17. Shi, X.; Wang, S.; Meshinchi, S.; Van Antwerp, M. E.; Bi, X.; Lee, I.; Baker, J. R., Jr. Dendrimer-Entrapped Gold Nanoparticles as a Platform for Cancer-Cell Targeting and Imaging. Small 2007, 3, 1245-1252.

18. Manna, A.; Imae, T.; Aoi, K.; Okada, M.; Yogo, T. Synthesis of DendrimerPassivated Noble Metal Nanoparticles in a Polar Medium: Comparison of Size between Silver and Gold Particles. Chem. Mater. 2001, 13, 1674-1681.

19. Kim, Y.-G.; Oh, S.-K.; Crooks, R. M. Preparation and Characterization of 1-2 nm Dendrimer-Encapsulated Gold Nanoparticles Having Very Narrow Size Distributions. Chem. Mater. 2004, 16, 167-172.

20. Shen, H.; Wang, S.; Xu, H.; Zhou, Y.; Gao, C. Preparation of Polyamide Thin Film Nanocomposite Membranes Containing Silica Nanoparticles via an in-Situ Polymerization of $\mathrm{SiCl}_{4}$ in Organic Solution. J. Membr. Sci. 2018, 565, 145-156.

21. Bowen, W. R.; Welfoot, J. S. Modelling the Performance of Membrane Nanofiltration-Critical Assessment and Model Development. Chem. Eng. Sci. 2002, 57, 1121-1137.

22. De Jubera, A. M.; Gao, Y.; Moore, J. S.; Cahill, D. G.; Marinas, B. J. Enhancing the Performance of Nanofiltration Membranes by Modifying the Active Layer with Aramide Dendrimers. Environ. Sci. Technol. 2012, 46, 9592-9599.

23. Labban, O.; Liu, C.; Chong, T. H.; Lienhard V, J. H. Fundamentals of Low-Pressure Nanofiltration: Membrane Characterization, Modeling, and Understanding the Multi- 
Ionic Interactions in Water Softening. J. Membr. Sci. 2017, 521, 18-32.

24. Long, Q.; Zhang, Z.; Qi, G.; Wang, Z.; Chen, Y.; Liu, Z.-Q. Fabrication of Chitosan Nanofiltration Membranes by the Film Casting Strategy for Effective Removal of Dyes/Salts in Textile Wastewater. ACS Sustainable Chem. Eng. 2020, 8, 2512-2522.

25. Zhang, H.; Taymazov, D.; Li, M.-P.; Huang, Z.-H.; Liu, W.-L.; Zhang, X.; Ma, X.H.; Xu, Z.-L. Construction of $\mathrm{MoS}_{2}$ Composite Membranes on Ceramic Hollow Fibers for Efficient Water Desalination. J. Membr. Sci. 2019, 592, 117369.

26. Cao, X.-L.; Yan, Y.-N.; Zhou, F.-Y.; Sun, S.-P. Tailoring Nanofiltration Membranes for Effective Removing Dye Intermediates in Complex Dye-Wastewater. J. Membr. Sci. 2020, 595, 117476.

27. Fang, C.; Sun, J.; Zhang, B.; Sun, Y.; Zhu, L.; Matsuyama, H. Preparation of Positively Charged Composite Nanofiltration Membranes by Quaternization Crosslinking for Precise Molecular and Ionic Separations. J. Colloid Interf. Sci. 2018, 531, 168-180.

28. Wu, H.; Lin, Y.; Feng, W.; Liu, T.; Wang, L.; Yao, H.; Wang, X. A Novel Nanofiltration Membrane with [MimAP] $\left[\mathrm{Tf}_{2} \mathrm{~N}\right]$ Ionic Liquid for Utilization of Lithium from Brines with High $\mathrm{Mg}^{2+} / \mathrm{Li}^{+}$Ratio. J. Membr. Sci. 2020, 603, 117997.

29. Bera, A.; Trivedi, J. S.; Jewrajka, S. K.; Ghosh, P. K. In Situ Manipulation of Properties and Performance of Polyethyleneimine Nanofiltration Membranes by Polyethylenimine-Dextran Conjugate. J. Membr. Sci. 2016, 519, 64-76.

30. Ang, M. B. M. Y.; Tang, C.-L.; De Guzman, M. R.; Maganto, H. L. C.; Caparanga, A. R.; Huang, S.-H.; Tsai, H.-A.; Hu, C.-C.; Lee, K.-R.; Lai, J.-Y. Improved 
Performance of Thin-Film Nanofiltration Membranes Fabricated with the Intervention of Surfactants Having Different Structures for Water Treatment. Desalination 2020, 481, 114352.

31. Fang, L.-F.; Zhou, M.-Y.; Cheng, L.; Zhu, B.-K.; Matsuyama, H.; Zhao, S. Positively Charged Nanofiltration Membrane Based on Cross-Linked Polyvinyl Chloride Copolymer. J. Membr. Sci. 2019, 572, 28-37.

32. Xu, P.; Hong, J.; Qian, X.; Xu, Z.; Xia, H.; Ni, Q.-Q. “Bridge” Graphene Oxide Modified Positive Charged Nanofiltration Thin Membrane with High Efficiency for $\mathrm{Mg}^{2+} / \mathrm{Li}^{+}$Separation. Desalination 2020, 488, 114522.

33. Zhao, F. Y.; Ji, Y. L.; Weng, X. D.; Mi, Y. F.; Ye, C. C.; An, Q. F.; Gao, C. J. HighFlux Positively Charged Nanocomposite Nanofiltration Membranes Filled with Poly(dopamine) Modified Multiwall Carbon Nanotubes. ACS Appl. Mater. Interfaces 2016, 8, 6693-700.

34. Soyekwo, F.; Zhang, Q.; Gao, R.; Qu, Y.; Lv, R.; Chen, M.; Zhu, A.; Liu, Q. Metal in Situ Surface Functionalization of Polymer-Grafted-Carbon Nanotube Composite Membranes for Fast Efficient Nanofiltration. J. Mater. Chem. A 2017, 5, 583-592.

35. Chong, J. Y.; Wang, R. From Micro to Nano: Polyamide Thin Film on Microfiltration Ceramic Tubular Membranes for Nanofiltration. J. Membr. Sci. 2019, $587,117161$.

36. Lv, Y.; Du, Y.; Chen, Z.-X.; Qiu, W.-Z.; Xu, Z.-K. Nanocomposite Membranes of Polydopamine/Electropositive Nanoparticles/Polyethyleneimine for Nanofiltration. $J$. Membr. Sci. 2018, 545, 99-106. 
37. Fang, W.; Shi, L.; Wang, R. Mixed Polyamide-Based Composite Nanofiltration Hollow Fiber Membranes with Improved Low-Pressure Water Softening Capability. J. Membr. Sci. 2014, 468, 52-61.

38. Gu, K.; Wang, S.; Li, Y.; Zhao, X.; Zhou, Y.; Gao, C. A Facile Preparation of Positively Charged Composite Nanofiltration Membrane with High Selectivity and Permeability. J. Membr. Sci. 2019, 581, 214-223.

39. Dong, L.; Fan, W.; Tong, X.; Zhang, H.; Chen, M.; Zhao, Y. A CO2-Responsive Graphene Oxide/Polymer Composite Nanofiltration Membrane for Water Purification. J. Mater. Chem. A 2018, 6, 6785-6791.

40. Dai, R.; Wang, X.; Tang, C. Y.; Wang, Z. Dually Charged MOF-Based Thin-Film Nanocomposite Nanofiltration Membrane for Enhanced Removal of Charged Pharmaceutically Active Compounds. Environ. Sci. Technol. 2020, 54, 7619-7628.

41. Yuan, B.; Zhao, S.; Hu, P.; Cui, J.; Niu, Q. J. Asymmetric Polyamide Nanofilms with Highly Ordered Nanovoids for Water Purification. Nat. Commun. 2020, 11, 6102. 42. Gao, S.; Zhu, Y.; Gong, Y.; Wang, Z.; Fang, W.; Jin, J. Ultrathin Polyamide Nanofiltration Membrane Fabricated on Brush-Painted Single-Walled Carbon Nanotube Network Support for Ion Sieving. ACS Nano 2019, 13, 5278-5290.

43. Gui, L.; Dong, J.; Fang, W.; Zhang, S.; Zhou, K.; Zhu, Y.; Zhang, Y.; Jin, J., Ultrafast Ion Sieving from Honeycomb-like Polyamide Membranes Formed Using Porous Protein Assemblies. Nano Lett. 2020, 20, 5821-5829.

44. Fang, W.; Shi, L.; Wang, R. Interfacially Polymerized Composite Nanofiltration Hollow Fiber Membranes for Low-Pressure Water Softening. J. Membr. Sci. 2013, 430, 
129-139.

45. Li, Y.; Wong, E.; Mai, Z.; Van der Bruggen, B. Fabrication of Composite Polyamide/Kevlar Aramid Nanofiber Nanofiltration Membranes with High Permselectivity in Water Desalination. J. Membr. Sci. 2019, 592, 117369.

46. Shi, Q.; Ni, L.; Zhang, Y.; Feng, X.; Chang, Q.; Meng, J. Poly(p-Phenylene Terephthamide) Embedded in a Polysulfone as the Substrate for Improving Compaction Resistance and Adhesion of a Thin Film Composite Polyamide Membrane. J. Mater. Chem. A 2017, 5, 13610-13624.

47. Yuan, B.; Jiang, C.; Li, P.; Sun, H.; Li, P.; Yuan, T.; Sun, H.; Niu, Q. J. Ultrathin Polyamide Membrane with Decreased Porosity Designed for Outstanding WaterSoftening Performance and Superior Antifouling Properties. ACS Appl. Mater. Interfaces 2018, 10, 43057-43067.

48. Sun, Z.; Wu, Q.; Ye, C.; Wang, W.; Zheng, L.; Dong, F.; Yi, Z.; Xue, L.; Gao, C. Nanovoid Membranes Embedded with Hollow Zwitterionic Nanocapsules for a Superior Desalination Performance. Nano Lett. 2019, 19, 2953-2959.

49. Bai, L.; Liu, Y.; Bossa, N.; Ding, A.; Ren, N.; Li, G.; Liang, H.; Wiesner, M. R. Incorporation of Cellulose Nanocrystals (CNCs) into the Polyamide Layer of Thin-Film Composite (TFC) Nanofiltration Membranes for Enhanced Separation Performance and Antifouling Properties. Environ. Sci. Technol. 2018, 52, 11178-11187.

50. Gong, G.; Wang, P.; Zhou, Z.; Hu, Y. New Insights into the Role of an Interlayer for the Fabrication of Highly Selective and Permeable Thin-Film Composite Nanofiltration Membrane. ACS Appl. Mater. Interfaces 2019, 11, 7349-7356. 
51. Yuan, S.; Zhang, G.; Zhu, J.; Mamrol, N.; Liu, S.; Mai, Z.; Van Puyvelde, P.; Van der Bruggen, B. Hydrogel Assisted Interfacial Polymerization for Advanced Nanofiltration Membranes. J. Mater. Chem. A 2020, 8, 3238-3245.

52. Shen, K.; Li, P.; Zhang, T.; Wang, X. Salt-Tuned Fabrication of Novel Polyamide Composite Nanofiltration Membranes with Three-Dimensional Turing Structures for Effective Desalination. J. Membr. Sci. 2020, 607, 118153.

53. Zhai, Z.; Jiang, C.; Zhao, N.; Dong, W.; Lan, H.; Wang, M.; Niu, Q. J. Fabrication of Advanced Nanofiltration Membranes with Nanostrand Hybrid Morphology Mediated by Ultrafast Noria-Polyethyleneimine Codeposition. J. Mater. Chem. A 2018, 6, 21207-21215.

54. Zhu, J.; Hou, J.; Yuan, S.; Zhao, Y.; Li, Y.; Zhang, R.; Tian, M.; Li, J.; Wang, J.; Van der Bruggen, B. MOF-Positioned Polyamide Membranes with a Fishnet-Like Structure for Elevated Nanofiltration Performance. J. Mater. Chem. A 2019, 7, 1631316322.

55. Zhang, Z.; Shi, X.; Wang, R.; Xiao, A.; Wang, Y. Ultra-Permeable Polyamide Membranes Harvested by Covalent Organic Framework Nanofiber Scaffolds: A Twoin-One Strategy. Chem. Sci. 2019, 10, 9077-9083.

56. Shen, K.; Cheng, C.; Zhang, T.; Wang, X. High Performance Polyamide Composite Nanofiltration Membranes via Reverse Interfacial Polymerization with the Synergistic Interaction of Gelatin Interlayer and Trimesoyl Chloride. J. Membr. Sci. 2019, 588, 117192.

57. Yang, H.; Yang, L.; Wang, H.; Xu, Z.; Zhao, Y.; Luo, Y.; Nasir, N.; Song, Y.; Wu, 
H.; Pan, F.; Jiang, Z. Covalent Organic Framework Membranes through a MixedDimensional Assembly for Molecular Separations. Nat. Commun. 2019, 10, 2101.

58. Peng, H.; Zhang, W. H.; Hung, W. S.; Wang, N.; Sun, J.; Lee, K. R.; An, Q. F.; Liu, C. M.; Zhao, Q. Phosphonium Modification Leads to Ultrapermeable Antibacterial Polyamide Composite Membranes with Unreduced Thickness. Adv. Mater. 2020, 32, e2001383.

59. Yuan, J.; Wu, M.; Wu, H.; Liu, Y.; You, X.; Zhang, R.; Su, Y.; Yang, H.; Shen, J.; Jiang, Z. Covalent Organic Framework-Modulated Interfacial Polymerization for Ultrathin Desalination Membranes. J. Mater. Chem. A 2019, 7, 25641-25649.

60. Wang, Z.; Wang, Z.; Lin, S.; Jin, H.; Gao, S.; Zhu, Y.; Jin, J. NanoparticleTemplated Nanofiltration Membranes for Ultrahigh Performance Desalination. Nat. Commun. 2018, 9, 2004.

61. Yao, Z.; Guo, H.; Yang, Z.; Qing, W.; Tang, C. Y. Preparation of NanocavityContained Thin Film Composite Nanofiltration Membranes with Enhanced Permeability and Divalent to Monovalent Ion Selectivity. Desalination 2018, 445, 115 122.

62. Ang, M. B. M. Y.; Trilles, C. A.; De Guzman, M. R.; Pereira, J. M.; Aquino, R. R.; Huang, S.-H.; Hu, C.-C.; Lee, K.-R.; Lai, J.-Y. Improved Performance of Thin-Film Nanocomposite Nanofiltration Membranes as Induced by Embedded PolydopamineCoated Silica Nanoparticles. Sep. Purif. Technol. 2019, 224, 113-120.

63. Kamiyama, Y.; Yoshioka, N.; Matsui, K.; Nakagome, K. New Thin-Film Composite Reverse Osmosis Membranes and Spiral Wound Modules. Desalination 
1984, 51, 79-92.

64. Ji, Y.-L.; An, Q.-F.; Weng, X.-D.; Hung, W.-S.; Lee, K.-R.; Gao, C.-J. Microstructure and Performance of Zwitterionic Polymeric Nanoparticle/Polyamide Thin-Film Nanocomposite Membranes for Salts/Organics Separation. J. Membr. Sci. 2018, 548, 559-571. 